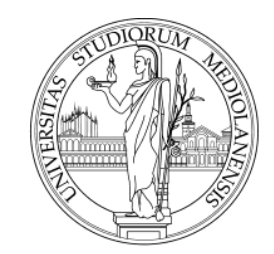

Università degli Studi di Milano
GRADUATE SCHOOL OF VETERINARY SCIENCES
FOR ANIMAL HEALTH AND FOOD SAFETY
Director: Prof. Vittorio Dell'Orto

Doctoral Program in Veterinary Clinical Sciences

Academic Year: 2010-2011

\title{
Tenovaginoscopic approach to the common digital flexor tendon sheath of adult cattle: Technique, normal findings and preliminary results in four clinical cases
}

Dott. Alberto Bertagnoli

Tutor:

Prof. Carlo Maria Mortellaro
Coordinator:

Prof. Angelo Belloli 

To Elena 



\section{Index}

\section{Introduction}

1.1 Common digital flexor tendon sheath .................................................

1.2 Tenosynovitis of the CDFTS ................................................................

1.3 Diagnosis of tenosynovitis of the CDFTS ......................................

1.3.1 Clinical Signs .................................................................................................

1.3.2 Ultrasonography ……………………………………………………...

1.3.3 Radiography ……………………………………………………...6

1.3.4 Synoviocentesis..............................................................................................

1.4 Treatment of tenosynovitis of the CDFTS …………………….......

1.4.1 Conservative therapy ……………………………………………………......

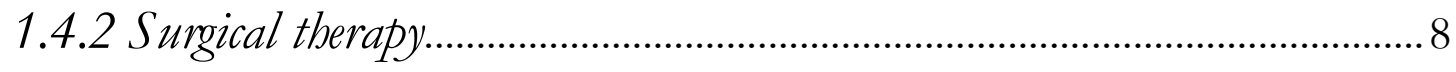

1.5 Arthroscopy …………………………………………………………………...

Aim of the study

Materials and methods ............................................................................15

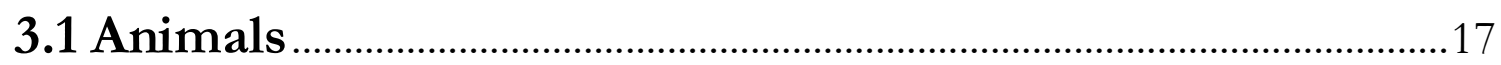

3.2 Instruments ......................................................................................

3.3 Anatomical study .............................................................................

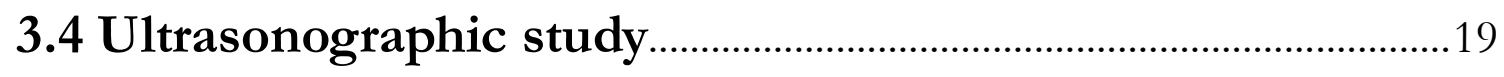

3.5 Tenovaginoscopic study ..................................................................

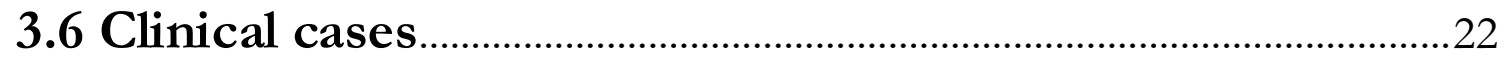

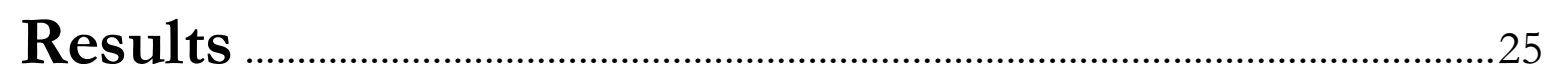

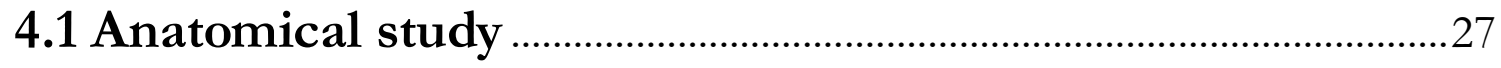

4.2 Ultrasonographic study.....................................................................

4.3 Tenovaginoscopic study ……………………………………............. 


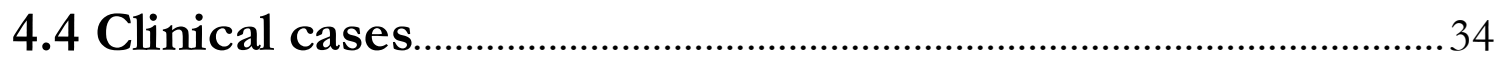

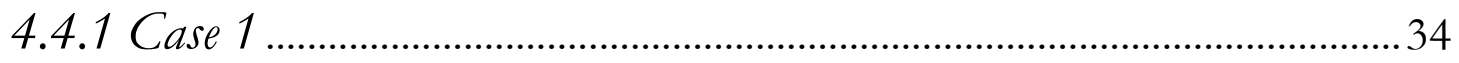

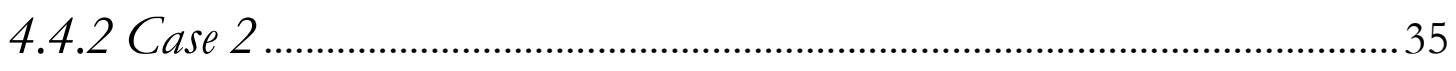

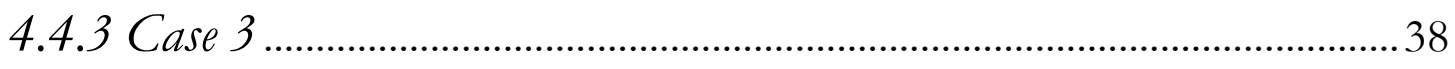

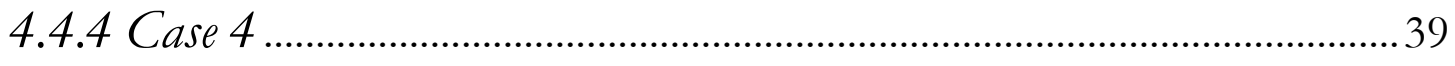

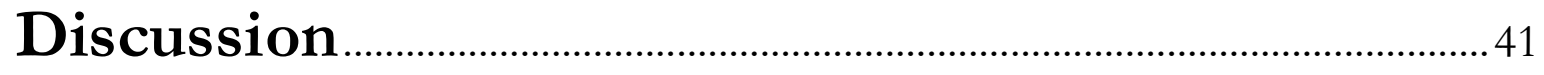

Conclusions …………………………………………………………..... 47

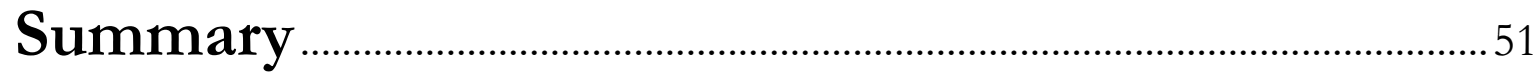

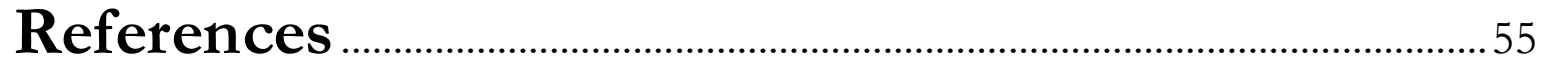

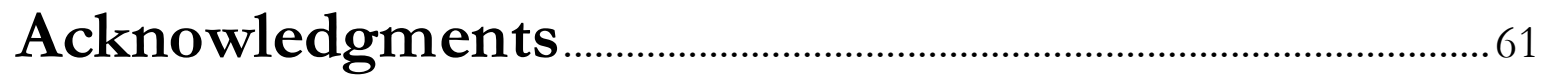




\section{CHAPTER 1}

\section{Introduction}





\section{Introduction}

Infection of synovial cavities of distal limbs is a common cause of lameness in cattle: the distal interphalangeal joint and the common digital flexor tendon sheath (CDFTS) are most frequently affected (Kofler, 1994; Kofler and Edinger, 1995; Anderson and St. Jean, 1996; Kofler, 1996; Bailey, 1997; Stanek, 1997; Weaver, 1997; Kofler, 2009). The diagnosis of disorders of the CDFTS has been based principally on a thorough clinical, ultrasonographic, radioghraphic examination and exploratory centesis of the swollen region (Kofler and Edinger, 1995; Kofler, 1996; Stanek, 1997; Kofler and Martinek, 2005).

In treating joint infection in man, arthroscopy is considered to offer several advantages over lavage and arthrotomy including improved visualization, identification of foreign material and infected or devitalized tissue, and access to a large area of synovial surfaces. Arthroscopy ensures an efficiently evaluated, cleaned, debrided and decompressed joint with minimal morbidity, reduced period of hospitalization and maximal functional recovery compared to other treatments (Wright et al., 2003). Also in cattle, arthroscopy has been described as an alternative minimal invasive diagnostic procedure in complicated arthritis, and it allows treatment of the joint cavity too (Munroe and Cauvin, 1994; Gaughan, 1996; Steiner et al., 1999; Starke et al., 2008).

The tenovaginoscopy of the CDFTS was first described in the horse by Nixon (1990). From this date onwards, this procedure has been used with either a diagnostic or an operative purpose. In cattle, a tenovaginoscopy of the CDFTS was recently described to treat a breeding bull (Morandi et al., 2009).

\subsection{Common digital flexor tendon sheath}

The CDFTS is a synovial structure which envelops the superficial and deep digital flexor tendon (SDFT and DDFT) from 6 to $8 \mathrm{~cm}$ proximal the dewclaws till the podothroclear bursa. The sheath is confined on its palmar/plantar surface by the Lig. anulare palmare/plantare, the proximal and distal digital annular ligaments, and the distal interdigital ligament. The unique anatomic arrangement of the tendons within this sheath gives rise to 3 compartments. The inner proximal compartment surrounds the DDFT proximal to the dewclaws, and is bordered by the SDFT and the ligamentum accessorium (branch of the $\mathrm{Mm}$. interossel); these last structures concur to create the manica flexoria that surrounds the DDFT palmar/plantar at the fetlock level. The outer proximal compartment surrounds the SDFT. Either this 2 compartments have a proximal pouch. At the end of the SDFT the proximal compartments merge together in the distal compartment (Anderson and St. Jean, 1996; Stanek, 1997; Kofler, 2009). A 
medial and a lateral pouch are situated between the proximal and distal digital annular ligaments. In the synovial cavity, there are three mesotendons between the SDFT and the sheath: the first is in a palmar/plantar medial position and originates from the fetlock region till the proximal limit of the outer proximal compartment, with a longitudinal direction; the second is in a dorsal median (related to the digit) position, between the end of the SDFT and the wall of the CDFTS; also this mesotendons has a longitudinal direction; the last mesotendon is in the lateral pouch and has a transversal direction. A short, $3 \mathrm{~mm}$ thick vinculum tendinum between the SDFT and the sheath is in a medial palmar/plantar position, just distal to the dewclaws. The CDFTS communicates with the contralateral only in the 10\% (Stanek, 1987; Lischer, 1999) at the fetlock level where they are separated by a thin septum.

\subsection{Tenosynovitis of the CDFTS}

Inflammation of synovial structures may be caused by trauma, injection of irritant chemicals, immune-mediated substances, or it may be secondary to a sepsis (Anderson et al., 1996; Dirksen et al., 2002). The phlogosis is caused by inflammatory mediators (such as tumor necrosis factor, prostaglandins, interleukins, and leukotrienes), and liberation of lysosomal enzymes (such as caseinase and collagenase) from synovial lining cells and white blood cells. These factors potentiate the destructive processes started by the first injury. Adhesions between the tendon and the sheath wall may result from continuous trauma or inflammation. Restrictive adhesions may cause recurrent pain and lead to decreased production (Anderson and St. Jean, 1996).

In cattle, two forms of tenosynovitis have been recognized: aseptic and septic. Aseptic tenosynovitis are uncommon and related to a repeated trauma, a rope or chain restraint, an overload of the contralateral impaired digit or limb (Anderson and St. Jean, 1996; Dirksen et al., 2002).

The incidence of septic tenosynovitis of the CDFTS is generally defined as not uncommon (Greenough et al., 1981b). The most detailed study was made by Stanek (1988), who reported 82 cases $(10,7 \%)$ of tenosynovitis among 766 hospitalized bovine patients in the Clinic of Orthopaedics in Ungulates, University of Vienna, from 1974 to 1987. Sixty-four cattle presented a septic tenosynovitis following a perforating trauma of the CDFTS, 4 had a metastatic septic tenosynovitis, 5 an aseptic tenosynovitis, and 9 were calves with septic tenosynovitis of different origin. Kofler (1994) reported 22 cases (4\%) suffering exclusively septic tenosynovitis of the CDFTS among 563 cattle admitted in the same clinic between the 1985 and the 1992. In another study about digital diseases in cattle, the tendons and/or the CDFTS were involved in 15\% of cases 
(Greenough et al., 1981a). Primary septic tenosynovitis of the CDFTS is caused by a penetrating wound. In tie stall, this condition is more frequent on the pelvic limb. In the last 20 years, the diffusion of free stall system instead of the tie stall, led this form to a lower prevalence. Today the most frequent form is the secondary septic tenosynovitis; this generally occurs as a sequel to a complicated digital infection such as pododermatitis circumscripta, white line infection, retroarticular abscess, interdigital phlegmon, sepsis of the distal interphalangeal joint, or sepsis of the podotrochlear bursa (Dirksen et al., 2002). Metastatic infections in adult cattle are uncommon (Anderson and St. Jean, 1996; Stanek, 1997; Dirksen et al., 2002). Pathogens isolated from septic tenosynovitis in cattle include: Actinomyces pyogenes, Escherichia coli, Fusobacterium necrophorum, Streptococcus spp., Staphylococcus spp., Bacterioides spp. (Anderson and St. Jean, 1996; Kofler, 1996; Desrochers, 2004; Starke et al., 2008).

\subsection{Diagnosis of tenosynovitis of the CDFTS}

\subsubsection{Clinical Signs}

The tenosynovitis of the CDFTS produces the classic signs of inflammation including heath and focal swelling localized to the palmar/plantar aspect of the pastern extending proximal 5-7 cm to the dewclaws, pain on palpation, lameness from moderate to non-weightbearing till recumbency, decreased milk production and feed intake (Anderson and St. Jean, 1996; Bertone, 1996; Weaver, 1997; Cook and Bertone, 1998). Aseptic tenosynovitis is associated with marked swelling of the CDFTS, but this is usually not warm and painful; the oedema and inflammation of the adjacent tissues are light or mild. Septic tenosynovitis guide to a firm, hot, painful swelling of the distal limb (Desrochers et al., 2001).

\subsubsection{Ultrasonography}

In the diagnosis of disorders of the CDFTS ultrasonography has been recognised as an important instrument. This technique allows the digital flexor tendons (DFT), the manica flexoria, the ligamentum accessorium, and the $\mathrm{mm}$. interossei to be clearly distinguished (Kofler and Edinger, 1995). They are highly echogenic structures with a strong linear pattern of the parallel fibre bundles with the exception of the $m m$ interossei, which was less echogenic than the DFT (Kofler, 2009). Normally, the lumina and wall of the synovia cannot be visualized with the exception of the outer proximal compartment, which appears as a narrow $(<2$ $\mathrm{mm}$ ) anechoic area around the SDFT, because of the low amount of synovial fluid. During a tenosynovitis of the CDFTS the increased volume of synovial fluid can be reliably detected by ultrasonography (Kofler and Edinger, 1995). The synovial cavity appears dilated with a thin echoic wall, which is displaced 
palmar/plantar from the articular surface. The three compartments could be distinguished as well as the medial and lateral pouches depending on the localization of the inflammation, and on the amount of the pathological synovial fluid. The echogenicity of the effusion ranges from anechoic to echoic depending on its nature (serous, serofribinous, fibrinous, purulent). Anechoic or hypoechoic content allows good differentiation of the synovial cavity from surrounding tissues, which are generally echoic, whereas echoic content does not (Kofler, 2009). The ultrasonography enables to identify lesions of the texture of the DFT (Kofler and Edinger, 1995; Kofler, 1996). In longstanding cases of septic inflammation, large amounts of fibrinogen are present in the synovial fluid; this precipitates in clotted fibrinous masses, which appear hypoechoic to echoic. The ability to differentiate the content of fluid-filled cavities from the surrounding echoic soft tissues depends on the density and cellular content, and echogenicity of the inflammatory exudates. However ultrasonography cannot characterize the type of exudates (Kofler, 2009). In septic disorders, there may be inflammatory oedema in the surrounding connective tissue, characterized by irregular areas of anechoic fluid accumulation separated by thin, weakly echoic septa (honeycomb appearance). Pathological communication between the two CDFTS can also be detected (Kofler, 2009).

\subsubsection{Radiography}

In case of tenosynovitis of the CDFTS, radiography may show soft tissue swelling localized to the palmar/plantar aspect of the distal limb region; it is also useful to evidence concomitant lesions of the regional bone structures: the metacarpo/metatarsophangeal joint, the proximal and distal sesamoid bones, the proximal and distal interphalangeal joints(Kofler, 1996). Two radiographic views of the digit must be taken: craniocaudal and lateromedial. Chronic presentation is common in food animals. For this reason, radiographic lesions are often obvious, but it should be taken in account that radiographic signs of degenerative joint disease take 10-14 days to many weeks to develop (Bertone, 1996; Desrochers, 2004).

\subsubsection{Synoviocentesis}

Aspiration of fluid from the CDFTS cavity with macroscopic evaluation, cytological and bacteriological analyses allows to identify and differentiate aseptic and septic tenosynovitis (Anderson and St. Jean, 1996; Cook and Bertone, 1998; Starke et al., 2008; Steiner, 2008; Kofler, 2009). The normal synovial fluid has a high transparency, a slightly yellowish colour and a high viscosity. The gross alterations in case of tenosynovitis are typically characterized by discoloration towards yellow/red, high turbidity, low viscosity, presence of smell (Kofler, 1996; Steiner, 2008). The synovial fluid in cattle with aseptic tenosynovitis is 
consistent with chronic inflammation: mild increase in percent of neutrophils and mild increase in protein concentration. The total protein level varies with the duration of the disease and it rises over the first 3 weeks of the phlogosis. An amount of cells over 30,000 cells $/ \mu \mathrm{L}$, with greater than $90 \%$ of neutrophils, is related to a septic tenosynovitis (Tab. 1) (Anderson and St. Jean, 1996; Bertone, 1996; Weaver, 1997; Starke et al., 2008). A bacterial culture of synovial fluid may be useful to identify the microorganism involved in the infection but often may gives false negative results (Anderson and St. Jean, 1996; Desrochers, 2004).

Table 1. Cytology of synovial fluid from normal, aseptic, and septic tenosynovitis.

\begin{tabular}{c|c|c|c}
\hline Variables & Normal (mean) & $\begin{array}{c}\text { Aseptic } \\
\text { Tenosynovitis } \\
\text { (mean) }\end{array}$ & $\begin{array}{c}\text { Septic } \\
\text { Tenosynovitis } \\
\text { (mean) }\end{array}$ \\
\hline Nucleated cell count (cells/ $\mu \mathrm{L})$ & 558.0 & 438.0 & $62,670.0$ \\
\hline Neutrophils $(\%)$ & 2.7 & 22.8 & 95.0 \\
\hline Lymphocytes $(\%)$ & 27.7 & 43.9 & 3.3 \\
\hline Monocytes $(\%)$ & 66.3 & 26.6 & 1.5 \\
\hline Eosinophils $(\%)$ & 0.3 & 0.0 & 0.2 \\
\hline Macrophages $(\%)$ & 3.0 & 6.7 & 0.0 \\
\hline Total protein $(\mathrm{g} / \mathrm{dL})$ & 1.1 & $2-4$ & 5.7 \\
\hline
\end{tabular}

Modified from (Anderson and St. Jean, 1996).

\subsection{Treatment of tenosynovitis of the CDFTS}

\subsubsection{Conservative therapy}

Conservative therapy may consist in administration of non steroidal antiinflammatory drugs (NSAIDS), warm-water hydrotherapy, pressure bandages. This therapy is indicated in course of aseptic tenosynovitis of the CDFTS, eventually with the addition of the tendon sheath drainage and lavage (Anderson and St. Jean, 1996).

In case of septic tenosynovitis, medical management alone (antibiotics and NSAIDS systemic administration, superficial wound care, hydrotherapy, and protective bandage) has a poor prognosis for resolution of tendon sheath infection. The excessive fibrin deposition, that characterizes the septic inflammation in cattle, prevents the antibiotics to achieve therapeutic concentrations in the synovial cavity (Verschooten et al., 1974; Desrochers et al., 2001). The choice of the antibiotic it should be related to the result of the cultural and sensitive analysis of the synovial fluid. However, culturing bacteria from this fluid is often difficult (Madison et al., 1991; Desrochers, 2004). An empiric antibiotic selection may be elected considering the common 
microorganisms involved in this inflammatory process as above indicated (Anderson and St. Jean, 1996). Penicillin is the antibiotic of choice for Actinomyces pyogenes, the most involved bacterium. In case of severely contaminated wound, an antimicrobial effective against gram-negative should be considered as well as cephalosporins and gentamycin, but in Italy the use of this last is forbidden in adult dairy cattle.

The standard systemic routes of administration are intravenous (IV), intramuscular (IM), and subcutaneous (SC). Other routes are: intraarticular injection, and regional intravenous perfusion. The main advantage of intraarticular injection is a higher minimal inhibitor concentration (MIC) at the site for a longer time period. In cattle intraarticular injections have been used empirically based on extrapolation from scientific data in other species. The regional intravenous perfusion of antimicrobials has many advantages: it reaches infected tissue by diffusion at a far greater concentration (10 folds) than after systemic IV administration. In addition, the local tissue concentrations remain higher than after systemic IV administration; thus a lower dose may be effective. The main disadvantage are the need to apply and maintain a good tourniquet and injection site morbidity (Desrochers, 2004).

\subsubsection{Surgical therapy}

The surgical treatment of septic tenosynovitis is considered to be more successful than the medical (Verschooten et al., 1974; Anderson and St. Jean, 1996; Desrochers et al., 2001). The surgery is generally made with the animal sedated and restrained in lateral recumbency, with an intravenous regional anaesthesia. A systemic antibiotic and anti-inflammatory therapy is always associated, as well as the bandage of the affected digit and the application of a wooden block on the contralateral healthy hoof. Several techniques may be used for surgical debridement, drainage, and lavage of the CDFTS. The selection of the treatment is based on severity and economic constraints (Anderson and St. Jean, 1996)

The tenovaginotomy of the CDFTS consists in a longitudinal median incision of the sheath, beginning to its proximal limit, proceeding medial to the dewclaw, and ending $2 \mathrm{~cm}$ proximal to the coronary band. It provides an optimal access for thorough debridement of the tendon sheath and tendon. After debridement and lavage, an indwelling passive or active drain can be let in place before to close the sheath, and it will be removed approximately 5 days after surgery. This may facilitate the drainage after surgery. The tenovaginotomy may cause disruption of the palmar/plantar common axial digital artery, vein, and nerve. These complications may lead to severe haemorrhage, skin necrosis, and permanent anaesthesia of the distal limb. Another complication is the dehiscence of the suture related to the high motion occurring in the palmar/plantar aspect 
of the fetlock. In case of the involvement of the DFT this technique can be associated to the partial or total tenectomy of the DFT. Tenectomy have a good prognosis only in a small number of cattle, and it may results in permanent hyperextension of the digit (Anderson and St. Jean, 1996; Desrochers et al., 2001). A different solution is the partial tenovaginotomy with the insertion of a plastic canula; this technique is associated to the formation of multiple loculated abscesses along the CDFTS and extensive thickening of the distal limb (Desrochers et al., 2001; Dirksen et al., 2002).

Some Authors prefer to use an indwelling multifenestrated lavage system into the CDFTS. Two incisions of about $1.5 \mathrm{~cm}$ are made in the proximal and distal part of the CDFTS. From these incisions the inflammatory fluid and the fibrin depots are grossly drained. Then the catheter is placed with the fenestrated part into the sheath and the extremities exiting from the 2 incisions. The distal end of the catheter is closed. This multifenestrated drain allows the lavage of the CDFTS for 5-7 days after surgery. A good-to excellent prognosis for long term productive soundness may be given with this technique. The possible complication is an ascending infection of the DFT, and a limitation is the cost of the daily wound and bandage management (Anderson and St. Jean, 1996; Anderson et al., 1997; Desrochers et al., 2001).

The most invasive surgical approach to the septic tenosynovitis of the CDFTS is the digit amputation. This may failure to resolve the tenosynovitis, and it may shorts the production life of the patient (Anderson and St. Jean, 1996; Desrochers et al., 2001).

\subsection{Arthroscopy}

Arthroscopy in cattle is usually considered an elective procedure. Experiences have increased the acceptance of bovine arthroscopy as a viable alternative to arthrotomy, and cattle owners are more educated with regard to the availability of arthroscopy at most referral hospitals. Techniques of arthroscopic examination of bovine joints are similar to those described for horses. Differences generally are found in the preoperative preparation of the patient, the techniques of diagnosing joint-origin disorders, and perhaps in degree of inflammatory response of the joints in cattle as compared to horses (Gaughan, 1996). Arthroscopy finds three indications in cattle: diagnosis, treatment of septic arthritis and osteochondrosis (Munroe and Cauvin, 1994; Gaughan, 1996; Steiner et al., 1999). Arthroscopy examination should be considered when other diagnostic measures are inconclusive, and if a complete evaluation of a joint is desired with kind regard to the prognosis of the involved tissues. Arthroscopy 
may be the most appropriate, expeditious treatment for septic arthritis and osteochondrosis (Gaughan, 1996).

In horse, tenovaginoscopy of the CDFTS is used for diagnosis and treatment of aseptic and septic digital tenosynovitis, release of the lig. anulare palmare/plantare, and it is useful in lavage, adherence debridement, removal of foreign material and devitalised tissue (Nixon, 1990; Frees et al., 2002; Nixon, 2002; Wright et al., 2003; Fraser and Bladon, 2004; Edinger et al., 2005; Lopes et al., 2006). The entry portal for routine tenovaginoscopy of the CDFTS is on the palmarolateral/plantarolateral surface immediately distal to the lig. anulare palmare/plantare (Fig. 1), this entrance allows examination of most regions of the sheath, and second instrument portals can be made proximal to the lig. anulare palmare/plantare under endoscopic view (Nixon, 2002). Other Authors (MCIlwraith, 1990; Lopes et al., 2006) used an arthroscope access portal just proximal to the lig. anulare palmare/plantare.

In cattle, Morandi et al. (2009) described the successful use of tenovaginoscopy for exploration and controlled lavage of septic tenosynovitis of the CDFTS in a breeding bull.

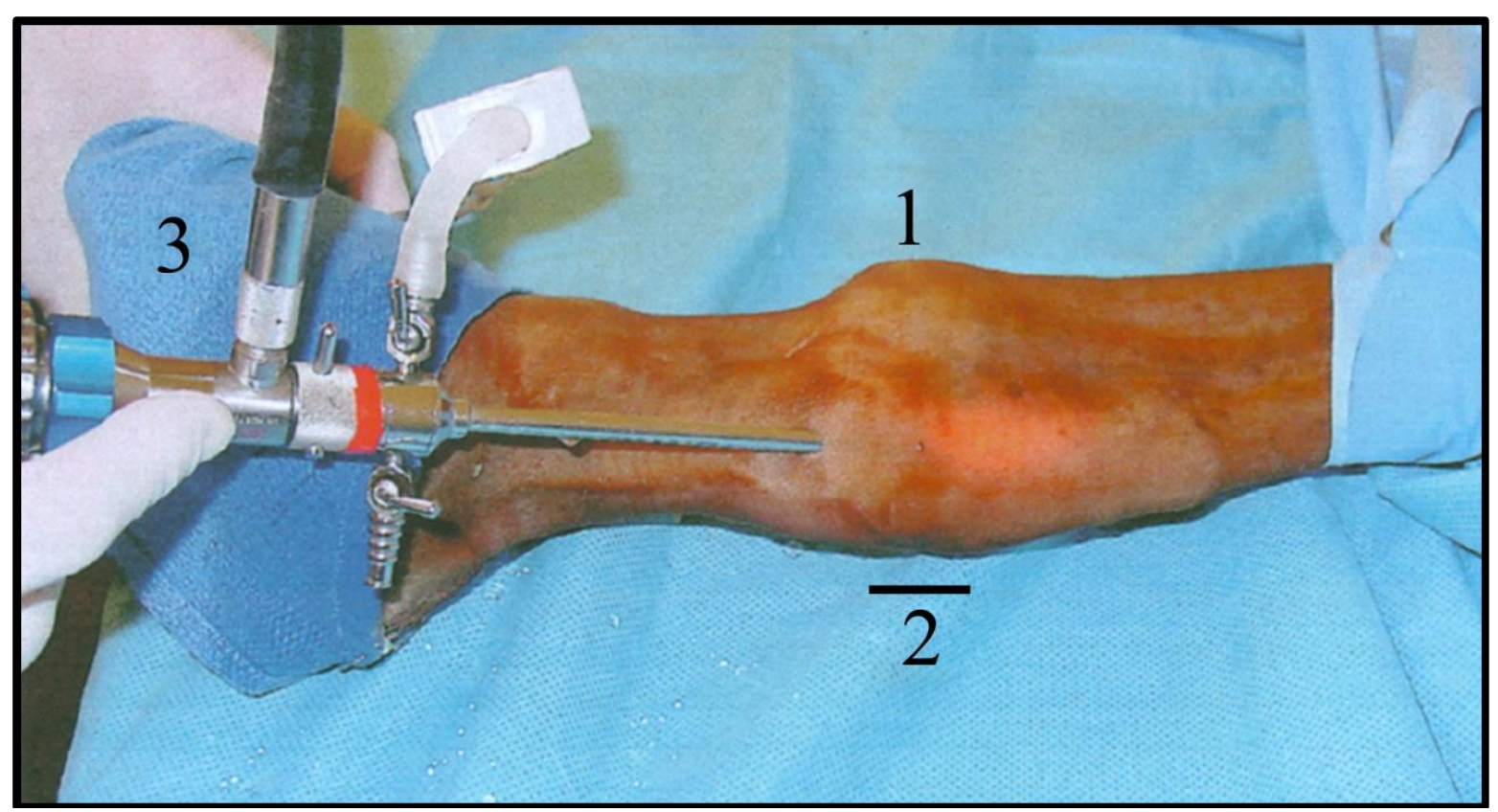

Figure 1. Endoscopic examination of the common digital flexor tendon sheath in a horse using an arthroscope access portal distal to lig. anulare plantare; 1, dorsal surface of fetlock; 2, width of lig. anulare palmare/plantare; 3 , heel bulb.

Modified from (Nixon, 2002). 


\section{CHAPTER 2}

\section{Aim of the study}





\section{Aim of the study}

The aim of this study is to describe a tenovaginoscopic approach of the bovine CDFTS. In order to achieve this goal, we performed first an anatomical and an ultrasonographic study of this synovial structure, followed by the tenovaginoscopy. This was carried out on healthy cadaveric distal limbs of dead cows. Then we described the arthroscopic findings in four cattle suffering from septic tenosynovitis of the CDFTS submitted for a tenovaginoscopic approach to the Clinic for Ruminants of Bern. 



\section{CHAPTER 3}

\section{Materials and methods}





\section{Materials and methods}

\subsection{Animals}

The anatomical, ultrasonographic and endoscopic study was undertaken using 27 healthy cadaver feet from seven adult dairy cows (13 fore and 14 hind feet). Of the seven cows, two were Red Holstein, one was Holstein Friesian, two were Simmental x Red-Holstein, and two were Swiss Braunvieh. The age of the cows ranged from 2 to 7 years. The feet were amputated at the carpal/tarsal joint, they were clipped and shaved, and the skin cleaned; the feet were preserved at a temperature of $0-3{ }^{\circ} \mathrm{C}$ until they were used ( $\max 3$ days after the death of the cow).

Four dairy cattle submitted to the Clinic for Ruminants at Berne University for treatment of septic tenosynovitis were used for the endoscopic study of diseased CDFTS.

\subsection{Instruments}

For the ultrasonographic study, a real-time B-mode linear scanner (Esaote Mylab $30 \mathrm{Vet}$ ) with a $15-10 \mathrm{MHz}$ linear array transducer was used. All the arthroscopic instruments and devices were manufactured by Karl Storz. We used a rigid, $30^{\circ}$ arthroscope with a length of $18 \mathrm{~cm}$ and an outer diameter of $4 \mathrm{~mm}$, and a sleeve with an outer diameter of $5.5 \mathrm{~mm}$ with 2 connections (Fig. 2). The instrument was equipped with an irrigation system (ExactaVet) as well as a video recording device. An Endovision Veterinary Video Camera transmitted the endoscopic pictures to the colour screen. The use of the AIDA-System (Advanced Image and Data Archiving System) allowed the continuous digital recording of the endoscopic findings for further analysis later.

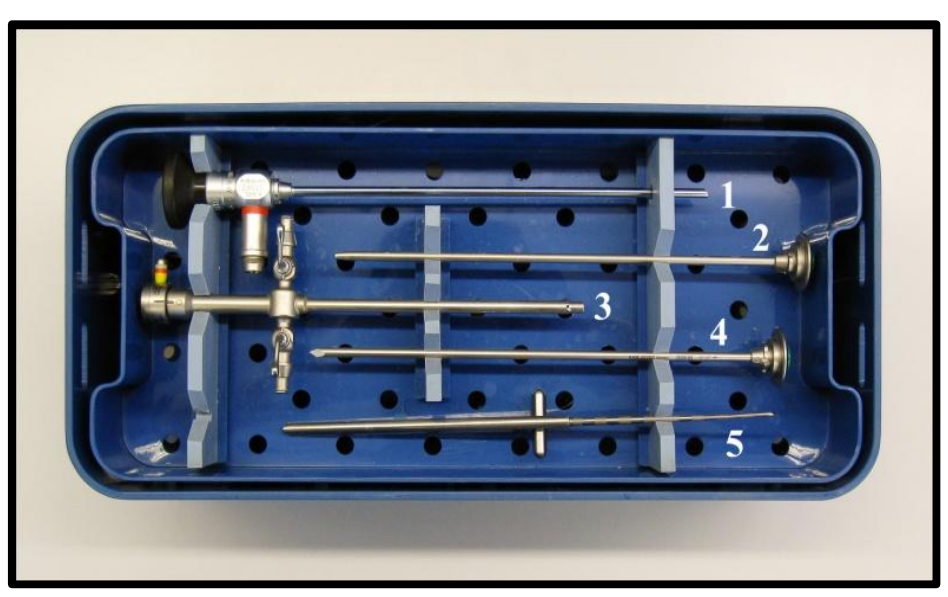

Figure 2. The arthroscopic kit: 1, arthroscope; 2, blunt trocar; 3 , sleeve with two connections; 4, sharp trocar; 5, ancillary instrument. 


\subsection{Anatomical study}

Three feet ( 1 right fore and 2 hind, right and left) were assigned to the anatomical study. The left hind foot was simply dissected to show the normal aspect of the CDFTS, and then the synovial cavity was opened, the DFT dissected and dislocated distal to show the slot-shaped opening of the manica flexoria.

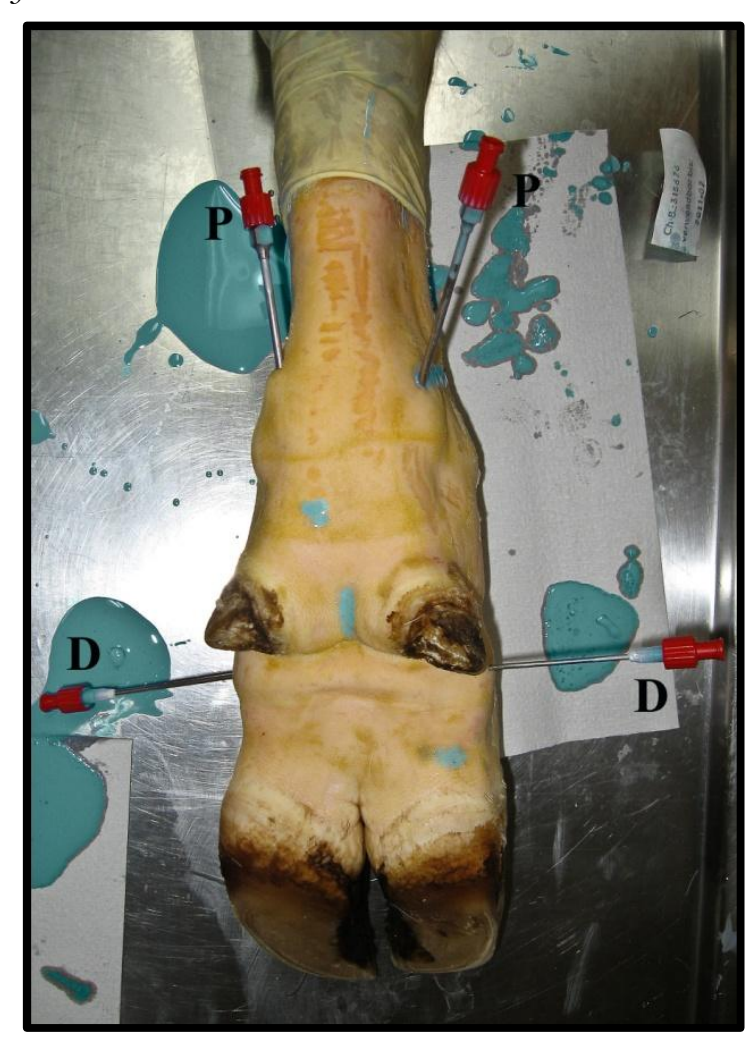

Figure 3. Silicon injection of the right hind foot; $\mathrm{P}$, proximal needle; $\mathrm{D}$, distal needle; in green the silicon
The CDFTS of the right feet were injected with a two-component silicone rubber (Silicon Elastosil RT K), that has an excellent flowability and it vulcanizes at room temperature. For her preparation, we mixed the silicone with silicon oil ( $70 \%$ of the silicone weight), then a little bit of green pigment paste and, finally, we added the hardener (4\% of the silicon weight). The silicone solution remained fluid and injectable for about 10 minutes, then it became to harden. For the injection two needles were inserted in the synovial cavity: one proximal for the initial silicone injection, and one distal, to drain the synovial fluid. This allows the silicone to completely fill the synovial cavity. The proximal needle (14 G x $80 \mathrm{~mm}$ ) was placed in the CFDTS proximal pouch, 5-6 $\mathrm{cm}$ proximal to the dewclaws in a palmarolateral/ plantarolateral position, between the DFT and the $\mathrm{mm}$. interossei, with a proximal to distal direction. The distal needle was introduced $1.5 \mathrm{~cm}$ distal to the dewclaws on the palmar/plantar aspect, between the distal ligament of dewclaws and the DFT, with a lateral to medial direction (Fig. 3). We injected the CDFTS with about $40 \mathrm{~mL}$ of green silicon. Twenty $\mathrm{mL}$ of silicon were first injected through the proximal needle, and when the synovial fluid ended to drip from the distal needle, this was closed. The remaining $20 \mathrm{~mL}$ were injected from the distal needle closing the proximal. After the injection, both the needles were closed by a cap (Fig. 3) and left in place till the dissection; the digit was then flexed and extended to facilitate the distribution of the silicone in the CDFTS. The specimens were kept in cold water $\left(10-15^{\circ} \mathrm{C}\right)$ for one day to favourite the silicone hardening, and then they were topographically dissected to show the CDFTS aspect. In the right hind 
limb both the CDFTS were injected, in the right fore foot only the lateral, while the medial CDFTS was removed.

After the dissection, the injected specimens were submitted to a conservation process. First they were placed in a formaldehyde solution (10\%), and then they underwent to a PEG (polyethylene glycol) conservation procedure. This is based on the extraction of all tissue-water, so no further metabolism process can go on in the specimen, and the tissues undergo no change any more. The tissue-water is directly replaced with an impregnating agent vacuum sealed: polyethylene glycol (PEG). This is possible due to the higher vapour pressure of the tissuewater than the PEG; that allows the direct distillation of the tissue water and the immediate replacement by PEG. This procedure prevents the volume and consistency changes of the preparation. Furthermore, PEG is chemical inert, thus there are no secondary changes of the preparations as well. After this process there is no shrinking to see and the preparation remains flexible. An important fact: polyethylene glycol is not harmful to health.

Photographs were taken of each prepared specimens (Panasonic, Lumix, DMCFZ50).

\subsection{Ultrasonographic study}

For the ultrasonographic and endoscopic study we used 24 feet (12 fore and 12 hind). Ultrasonography of the CDFTS was performed as described by Kofler and Edinger (1995), but the length of the probe $(4.5 \mathrm{~cm})$ allowed us also the visualization of the sagittal planes distal to the dewclaws. The examination started with transversal and sagittal sonograms of the CDFTS proximal to the dewclaws, and then distal. After the ultrasonography of the normal CDFTS, each synovial cavity was injected with $36-40 \mathrm{~mL}$ of $0.9 \% \mathrm{NaCl}$ solution using a $0.9 \mathrm{~mm} \times 40 \mathrm{~mm}$ needle, positioned $4-5 \mathrm{~cm}$ proximal to the dewclaws between the DFT and the mm. interossei, in a proximal to distal direction (Fig. 4).

\subsection{Tenovaginoscopic study}

Tenovaginoscopy of the injected CDFTS was undertaken immediately after the ultrasonography of the injected CDFTS. A $1-\mathrm{cm}$ skin incision was made $4-5 \mathrm{~cm}$ proximal to the dewclaws in the midline of the respective DFT. The sleeve with a blunt trocar was introduced into the proximal pouch of the CDFTS (Fig. 4), just proximal to the lig. anulare palmare/plantare, and advanced along the whole of its length in a distal direction palmar/plantar to the SDFT. The arthroscope was then introduced into the sleeve, and the CDFTS examined in the following 


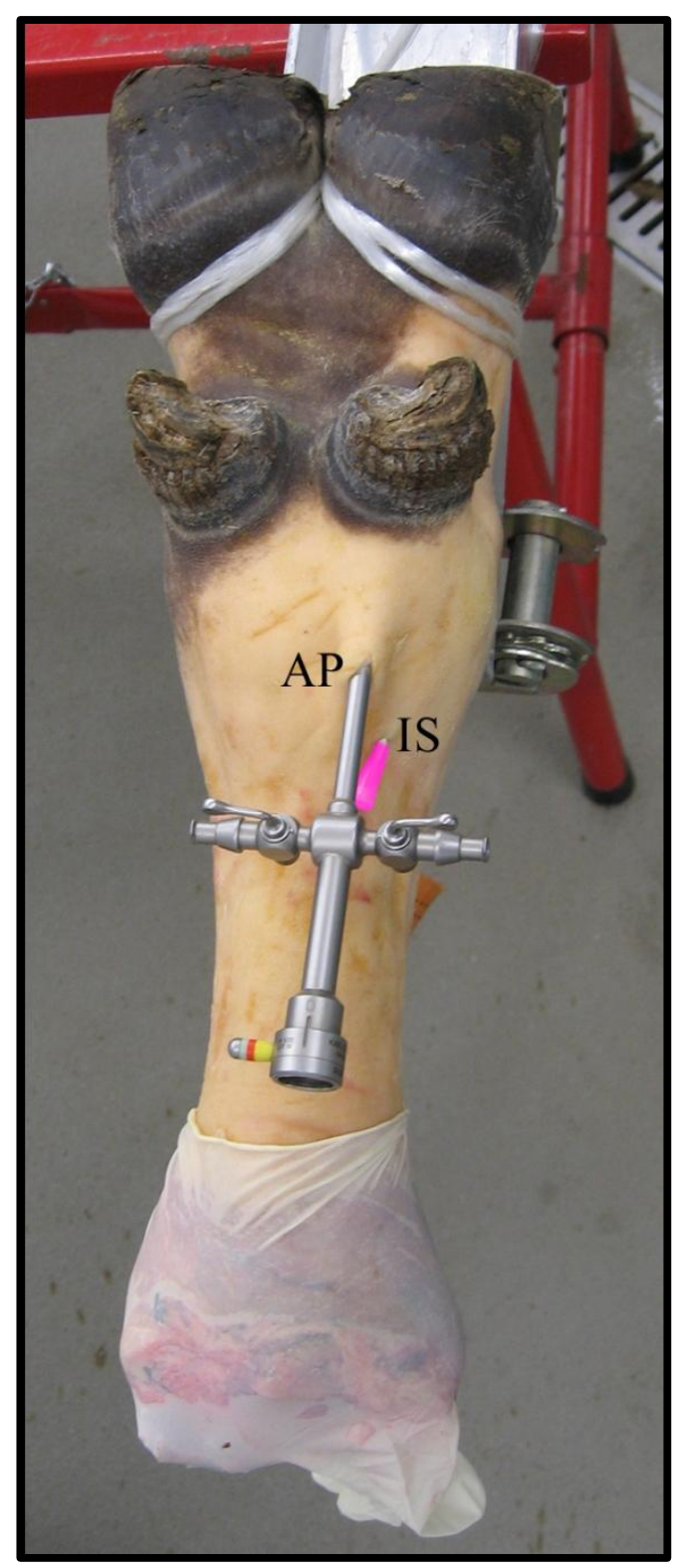

order: palmar/plantar to the SDFT from distal to proximal, then dorsal to the SDFT from proximal to distal and back, and finally, only in the hind feet, between the SDFT and the DDFT.

In each sheath, images were taken at 4 defined positions: position 1 (P1) was distal and position 2 (P2) proximal to the dewclaws on the palmar/plantar aspect of the SDFT. At position 3 (P3), the view was of the dorsal aspect of the manica flexoria, and at position 4 (P4), only in the hind feet, between the SDFT and the DDFT (Fig. 5). In the first 16 feet ( 8 fore and 8 hind), we made the tenovaginoscopy of only 1 CDFTS per foot. In the remaining 8 feet (4 fore and 4 hind) we undertook the tenovaginoscopy of both the CDFTS of a foot. In total we made 32 tenovaginoscopies (Tab. 2).

At the end of the procedure, both the CDFTS of a foot were dissected to verify the anatomical structures present.

Figure 4. Palmar view of a left cadaveric fore foot prepared for tenovaginoscopy of the lateral common digital flexor tendon sheath (CDFTS); IS, injection site of the CDFTS; AP, arthroscope access portal with the sleeve inserted into the CDFTS.

Table 2. Resume of tenovaginoscopies performed during the tenovaginoscopic study.

\begin{tabular}{c|cc|cc|cc|cc|c}
\hline & & & & & & & & Total \\
\cline { 4 - 10 } Foot & \multicolumn{2}{|c|}{ 6 Left fore } & \multicolumn{2}{|c|}{ 6 Left hind } & \multicolumn{2}{|c|}{ 6 Right fore } & \multicolumn{2}{|c|}{ 6 Right hind } & 24 \\
\hline Digit & Lateral & Medial & Lateral & Medial & Lateral & Medial & Lateral & Medial & \\
\hline CDFTS & 6 & 6 & 6 & 6 & 6 & 6 & 6 & 6 & 48 \\
\hline $\begin{array}{c}\text { Tenovagi } \\
\text { noscopy }\end{array}$ & 4 & 4 & 4 & 4 & 4 & 4 & 4 & 4 & 32 \\
\hline
\end{tabular}




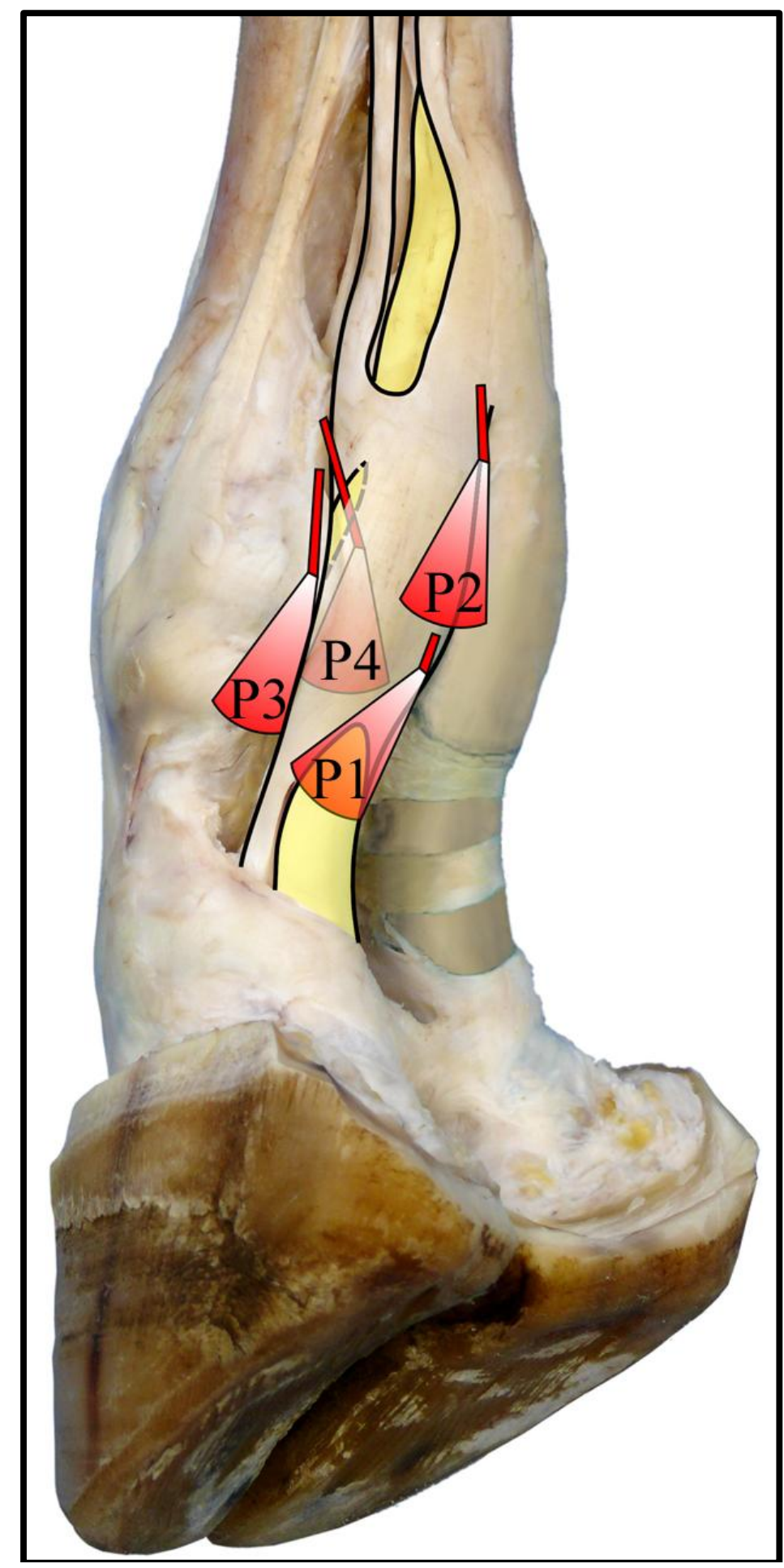

Figure 5. Schematic representation of the defined 4 positions of the tip of the arthroscope for taking images (mediopalmar projection of a right fore foot). The superficial digital flexor tendon is outlined with a black line; the deep digital flexor tendon is depicted in yellow; the dotted black line represents the position of the slot-shaped opening of the manica flexoria. The red cones represent the view angles of the arthroscope at the 4 defined positions P1 to P4. 


\subsection{Clinical cases}

Four adult cattle were referred to the Clinic for Ruminants at Berne University due to septic tenosynovitis of the CDFTS. In all cases, the pathogenesis was a penetrating puncture wound. The patients were submitted to clinical, radiographic and ultrasonographic examination. Centesis of the affected sheath was made for cytology.

Patients were fasted for $24 \mathrm{~h}$. General anaesthesia was induced with xylazine (Xylazin, Streuli, $0.2 \mathrm{mg} / \mathrm{kg}$ IV), butorphanol (Morphasol-10, Graeub; 0.05 $\mathrm{mg} / \mathrm{kg} \mathrm{IV}$ ), ketamine (Ketanarkon 100, Streuli; $3 \mathrm{mg} / \mathrm{kg}$ IV), and lidocaine (Lidokain 2\%, Streuli; bolus of $1.5 \mathrm{mg} / \mathrm{kg}$ IV) followed by intratracheal intubation and maintenance with a mixture of isoflurane (Attane, Minrad; MAC 1.3) and oxygen, and a continuous intravenous in fusion of $1.8 \mathrm{mg} / \mathrm{kg}$ lidocaine. Surgery was performed in lateral recumbency with the affected limb positioned uppermost. The affected limb distal to the carpal/tarsal joint was prepared for aseptic surgery and draped. A semi-flexible indwelling catheter made from polytetrafluoroethylene, with an outer diameter of $1.7 \mathrm{~mm}$ and a length of 83 $\mathrm{mm}$, was introduced in the distal direction into the affected CDFTS with the catheter directed distally. A sample of synovial fluid was collected, and the CDFTS then injected with $30-40 \mathrm{~mL}$ of sterile physiological Ringer's solution and $10 \mathrm{~mL}$ of $2 \%$ lidocaine. Explorative tenovaginoscopy was performed as described for the cadaver specimens. Thereafter, a $14 \mathrm{G}$ x $40 \mathrm{~mm}$ injection needle was introduced into the CDFTS under visual control distal to the dewclaws. Through-and-through lavage in both directions alternating with dilatation irrigation flushing were performed, using 3 to $6 \mathrm{~L}$ of physiological Ringer's solution. At the end of the procedure, $12 \times 10^{6} \mathrm{IU}$ of sodium benzylpenicillin (Na-Penicillin, Streuli) and $10 \mathrm{~mL}$ of lidocaine were injected into the CDFTS. The arthroscope was removed and the skin incision was sutured with one simple interrupted suture, using USP 0 polydioxanone sulphate (PDSII, Ethicon) suture material. A wedge shaped wooden block was glued to the contralateral claw.

Aftercare included $30,000 \mathrm{IU} / \mathrm{kg}$ of sodium benzylpenicillin every 8 hours IV through an indwelling catheter in the jugular vein for 7 days, while $4 \mathrm{mg} / \mathrm{kg}$ of ketoprofen (Dolovet, Graeub) was administered orally once a day for 3-5 days. The following recommendations for further care after discharge from the clinic were given: administration of benzylpenicillin procaine $(30,000 \mathrm{IU} / \mathrm{kg} \mathrm{IM}$ daily, Procacillin, Veterinaria) until day 10 after surgery, removal of the skin sutures on day 11, removal of the wooden block on day 30 and stall confinement until day 60 after surgery.

A telephone inquiry with the owners of the involved cattle was made at 6 to 24 months after discharge. The owners were asked about complications and/or 
persisting lameness of the affected limb, production level, productivity in the herd and the reason for early removal from the herd. 

CHAPTER 4

Results 



\section{Results}

\subsection{Anatomical study}

The Fig. 7 shows and compares the three different anatomical preparations of the CDFTS. Fig. $7 \mathrm{a}$ is the left hind foot with its normal aspect before to complete the dissection to show the slot-shaped opening of the manica flexoria of the hind feet (Fig. 6). In Fig. 7a the limit of the not injected CDFTS and the surrounding ligaments are poorly visible. Fig. $7 \mathrm{~b}$ and $7 \mathrm{c}$ show the green silicon injected CDFTS. In particular in Fig. 7b is presented the right fore foot with the lateral injected CDFTS in green, and the medial excised exposing the SDFT and the DDFT; Fig. 7c shows the two injected CDFTS of the right hind foot, always in green. In this last specimen, the lig. anulare plantare was removed. At the fetlock level there is no continuity of the silicon filling the outer proximal compartment;

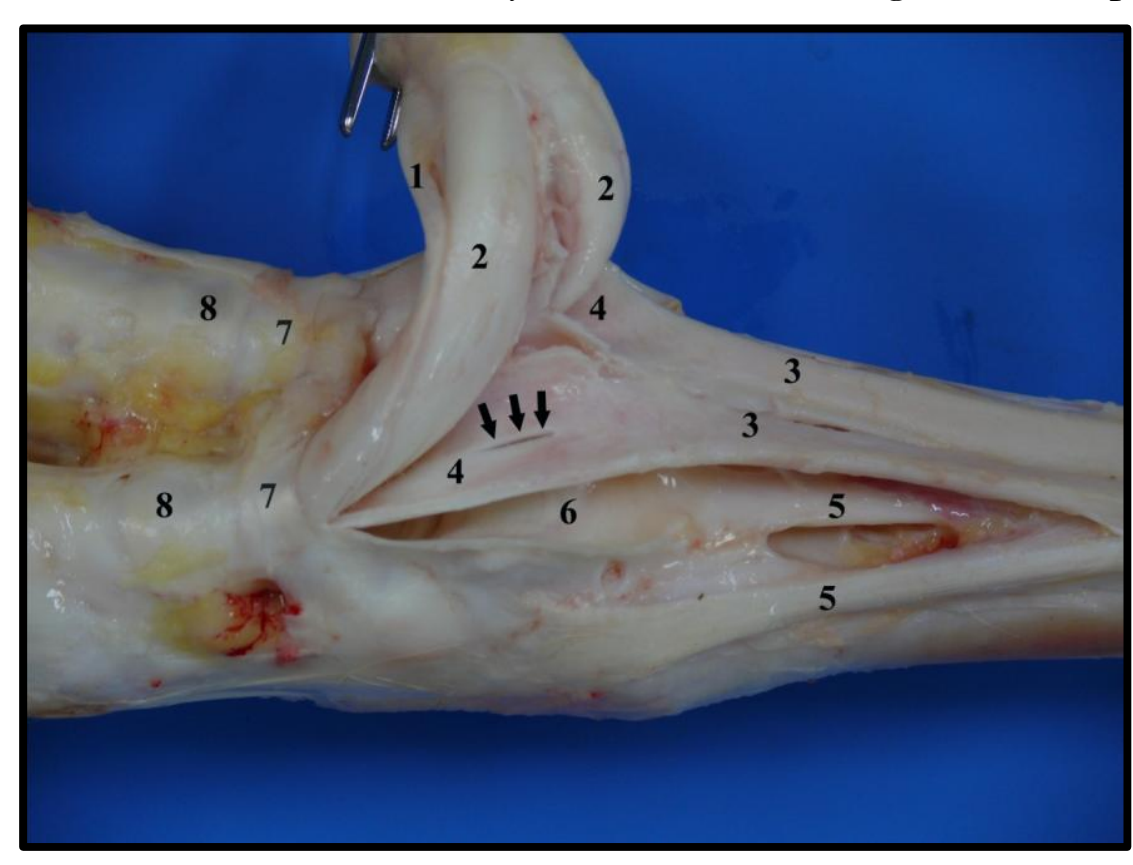

Figure 6. Left hind foot dissected to show the slot-shaped opening (highlighted by the black arrows) of the hind foot manica flexoria. The superficial and deep digital flexor tendon (1 and 2) were transversal dissected proximal, and dislocated plantar; the proximal part of the common digital flexor tendon sheath and the lig. anulare plantare were removed, the manica flexoria (4) was cut lateral. 3, lig. accessorium; 5, mm. interossei; 6, scutum proximale; 7, proximal digital annular ligament; 8, distal digital annular ligament. this is because the lig. anulare plantare strongly envelops the SDFT, not allowing the silicon to stay and harden in this position. Always in this specimen, we obtained the inner proximal compartment well distended and evident, as well as the pouches of the distal compartment (Fig. 8).

No communications between the CDFTS of the same feet were evidenced. 


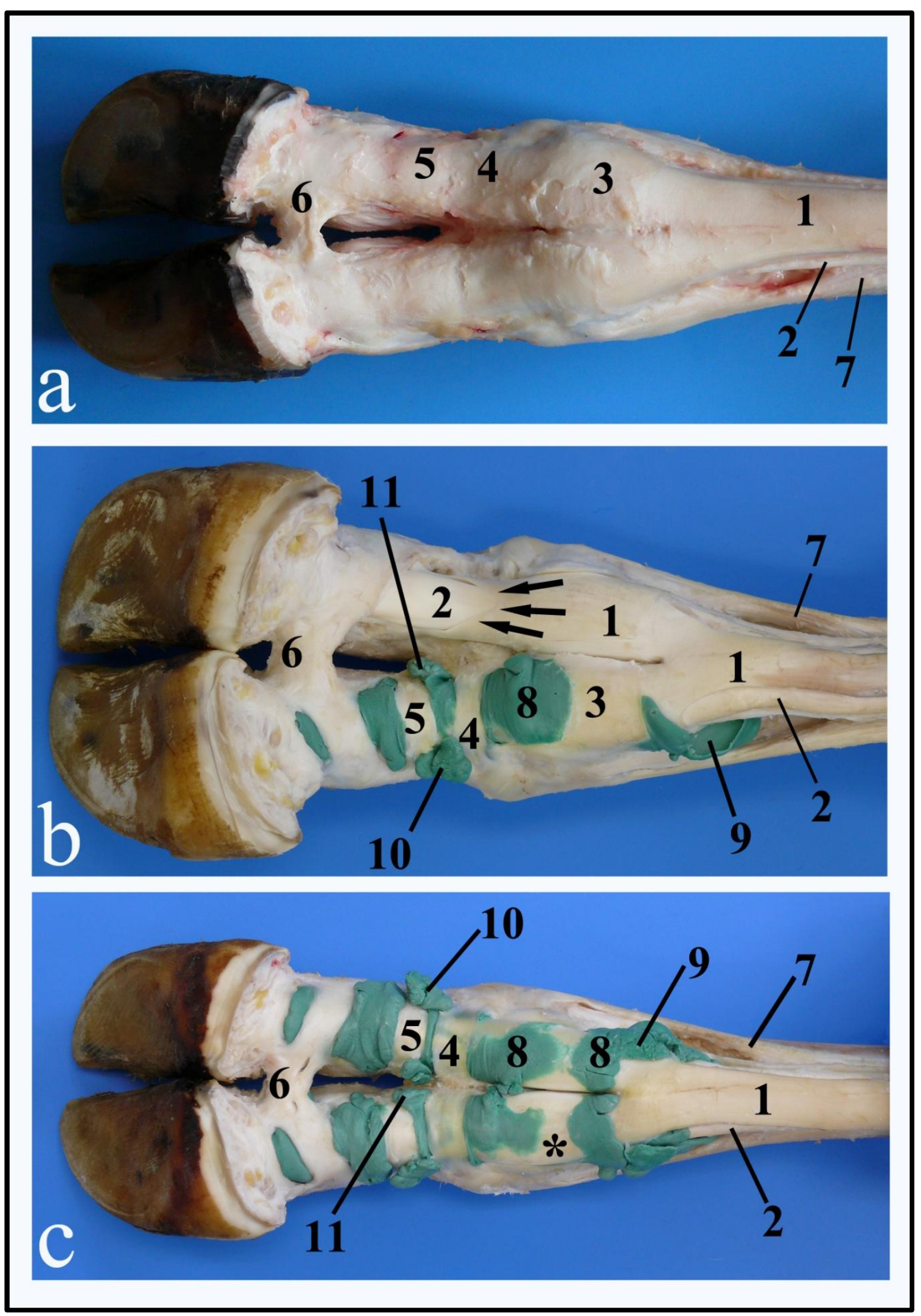


Figure 7. The three anatomical preparations. (a): Left hind limb with the normal common digital flexor tendon sheath (CDFTS) exposed; 1, superficial digital flexor tendon (SDFT); 2 deep digital flexor tendon; 3, lig. anulare palmare; 4, proximal digital annular ligament; 5, distal digital annular ligament; 6, distal interdigital ligament; 7, mm. interossei. (b): Right fore foot, in green the lateral CDFTS injected with silicon, while the medial CDFTS was excised and the underneath digital flexor tendons $(1,2)$ exposed; the end edge of the SDFT is highlighted by the black arrows; 8 , outer proximal compartment; 9, proximal pouch of the outer proximal compartment; 10, lateral pouch of the distal compartment; 11, medial pouch of the distal compartment. (c): Right hind limb, in green the both CDFTS injected with silicon; *, at the fetlock level, there is no continuity of the silicon in the outer proximal compartment, because the lig. anulare plantare (removed in this preparation) envelopes strongly the digital flexor tendons.

Figure 8. Anatomical preparation of the right hind limb, lateroplantar projection; in green the two CDFTS injected with green silicon. 1, proximal pouch of the inner proximal compartment; 2, outer proximal compartment; $2 \mathrm{~b}$, proximal pouch of the outer proximal compartment; 3 , superficial digital flexor tendon; 4, deep digital flexor tendon; 5, lig. accessorium; 6, mm. interossei; 7, lateral pouch of the distal compartment; 8, medial pouch of the distal compartment; 9, proximal digital annular ligament; 10, distal digital annular ligament; 11, distal interdigital ligament; *, at the fetlock level, there is no continuity of the silicon because the plantar annular ligament (removed in this preparation) envelopes strongly the digital flexor tendons.

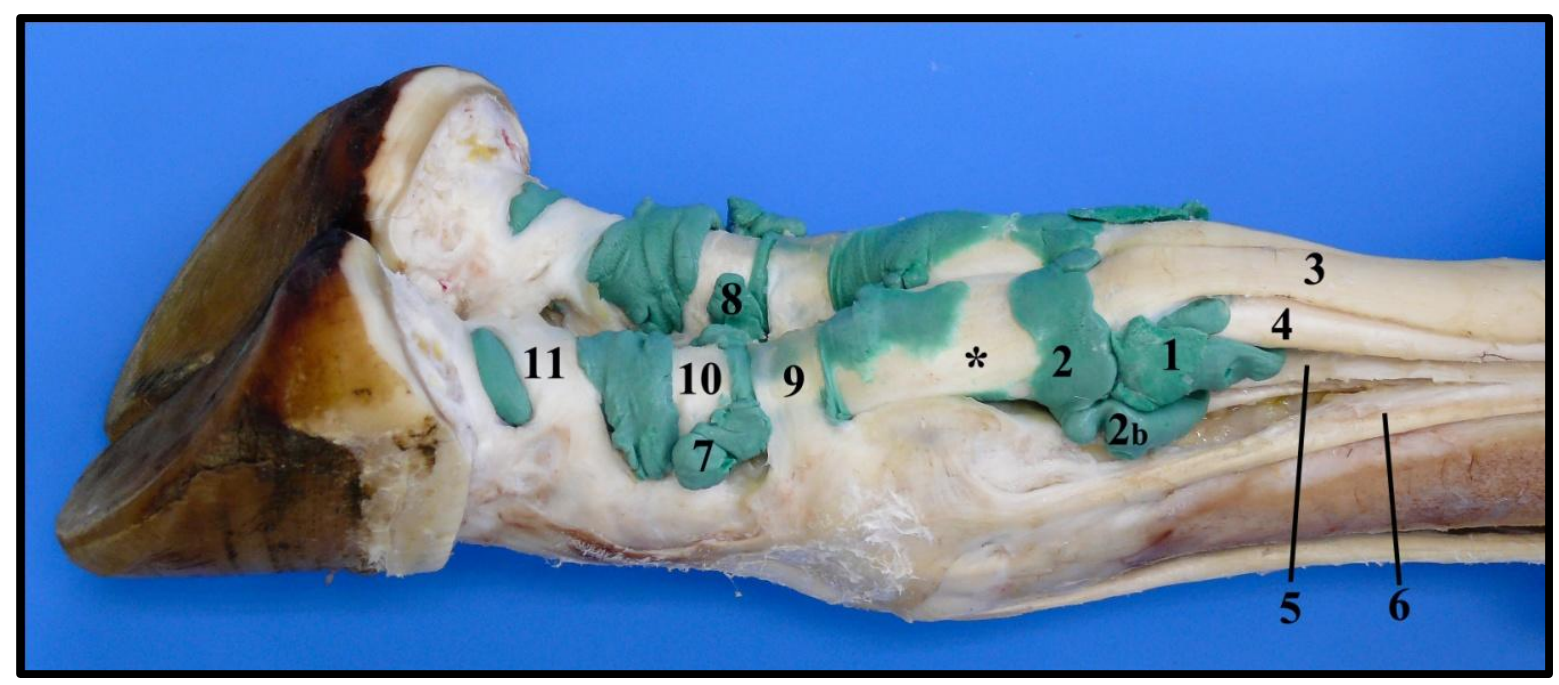




\subsection{Ultrasonographic study}

As stated by Kofler and Edinger (1995), the structures of the CDFTS were clearly visible only after the injection of $36-40 \mathrm{~mL}$ of a saline solution $(0.9 \%$ $\mathrm{NaCl}$. With the synovial cavity distended we could identify the SDFT, the DDFT, the lig. accessorium, the manica flexoria, the $\mathrm{mm}$. interossei, the inner and outer proximal compartments, the digital annular ligaments, and the lateral and medial pouches the distal compartment. (Fig. 9). The vinvulum tendinum, the mesotendons, the synovial villi, as well as the slot-shaped opening in the hind feet were not visualized.

No communications between the medial and lateral CDFTS were found in any of the feet.

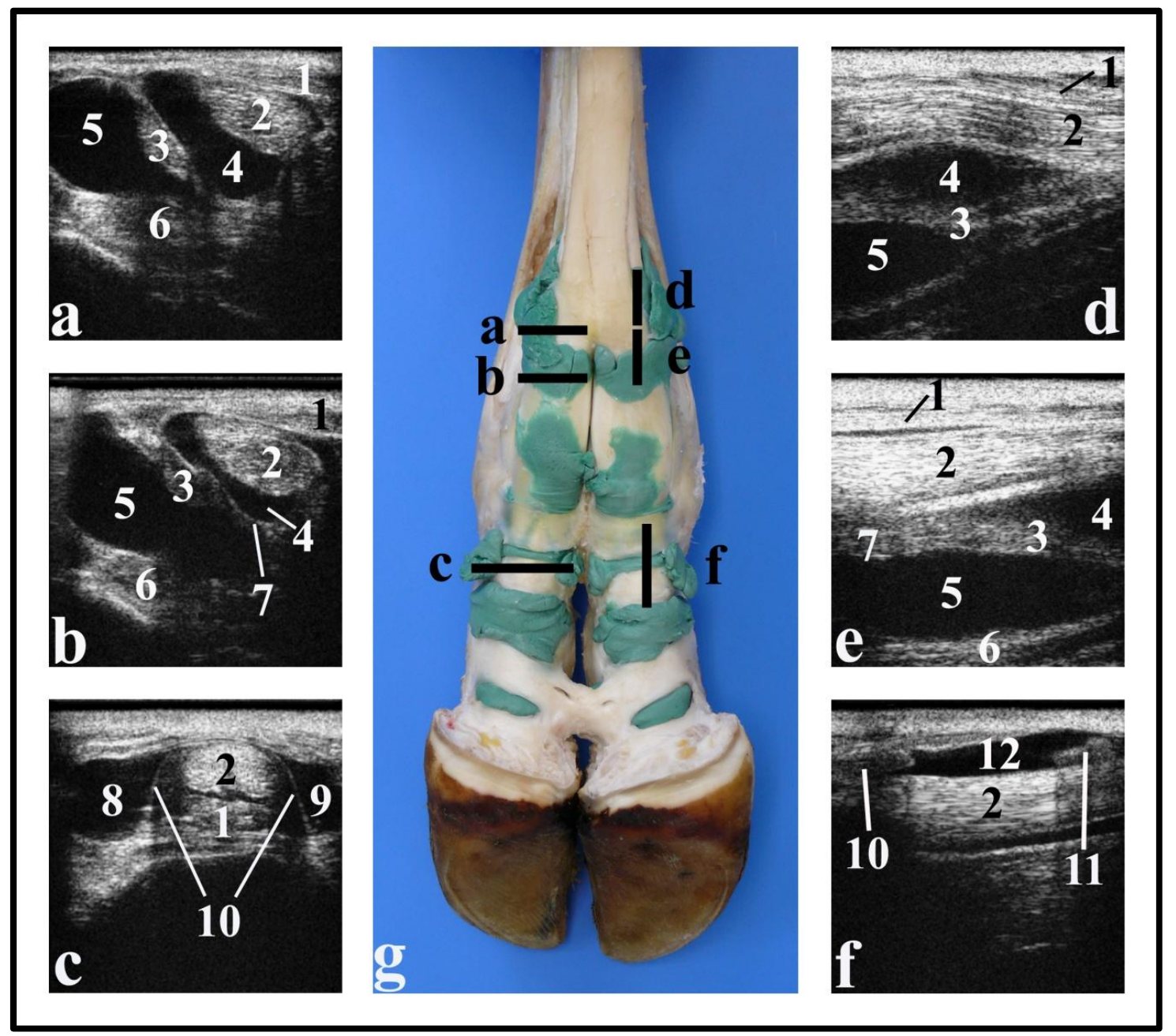

Figure 9. (a), (b), (c), (d), (e), (f): Transversal and sagittal sonograms of the injected common digital flexor tendon sheath (CDFTS) taken at the respective a, b, c, d, e, f black lines of Fig. 8/g.; 1, superficial digital flexor tendon; 2, deep digital flexor tendon; 3, lig. accessorium; 4, inner proximal compartment; 5, outer proximal compartment; 6, mm. interossei; 7, manica flexoria; 8: lateral pouch; 9, medial pouch; 10, distal digital annular ligament; 11, proximal digital annular ligament; 12, distal compartment. (g): Anatomical preparation of the right hind foot with the two CDFTS injected with green silicon. 


\subsection{Tenovaginoscopic study}

Examination of the synovial cavity took between 5 to 10 minutes per CDFTS. At P1, we were able to visualize the end edge of the SDFT and the DDFT appearing from it (Fig. 10/a), the distal and proximal digital annular ligaments, the pouches (medial and lateral) between them (Fig. 10/c,d), and a lateral mesotendon linking the SDFT to the CDFTS in the lateral pouch (Fig. 10/d). At P2, at the level of the fetlock joint, in the medial aspect, the presence of a palmar/plantar axial mesotendon that proceeded to the proximal end of the outer proximal compartment was evident. Distal to this mesotendon, a $3 \mathrm{~mm}$ thick vinculum tendinum was present between the SDFT and the CDFTS (Fig. 11/a). At P3, there were the insertion of the SDFT and a distal mesotendon (Fig. $11 / \mathrm{b}$ ) with villi synoviales. Proximally, at the level of the scutum proximale, a slotshaped opening in the manica flexoria was found in the hind feet (Fig. 11/c). This opening was absent in all the fore feet and also in the medial digits of the hind feet of one 3-year-old Swiss Braunvieh cow. The presence of the opening allowed the progression of the arthroscope into the inner proximal compartment of the CDFTS, situated between the SDFT and the DDFT. At this position, parts of both the SDFT and the DDFT were visible, as were villi synoviales at the insertion of the SDFT (Fig. 11/d). At P4, the arthroscope could be moved alongside the end edge of the SDFT, allowing better exploration of the distal lateral and medial aspects of the synovial cavity. All structures described above were characterized by a bright white colour and very distinct delineations (Fig. 10,11).

In 3 of the 32 tenovaginoscopy performed, the sleeve was introduced in the CDFTS perforating the SDFT. This happened because the arthroscope access portal was made on the lig. anulare palmare/plantare and not proximal to its limit. The lig. anulare palmare/plantare strongly surrounds the DFT, so the lumen of the CDFTS is almost virtual in this point. This leads to the direct perforation of the SDFT during the introduction of the sleeve in the CDFTS. In this position the arthroscope is in the inner proximal compartment, palmar/plantar the DDFT and it can only visualize the space between the SDFT and the DDFT (Fig. $10 / \mathrm{b}$ ); thus the sleeve needs to be carefully retracted and positioned in the outer proximal compartment, before to explore the synovial cavity. To recognize that the arthroscope was introduced in the right position, it is important to identify the end edge of the SDFT below the arthroscope and not above (Fig. 10/a,b). The final dissection of the feet always confirmed the tenovaginoscopic findings; no communications between the CDFTS of a same limb were found. 


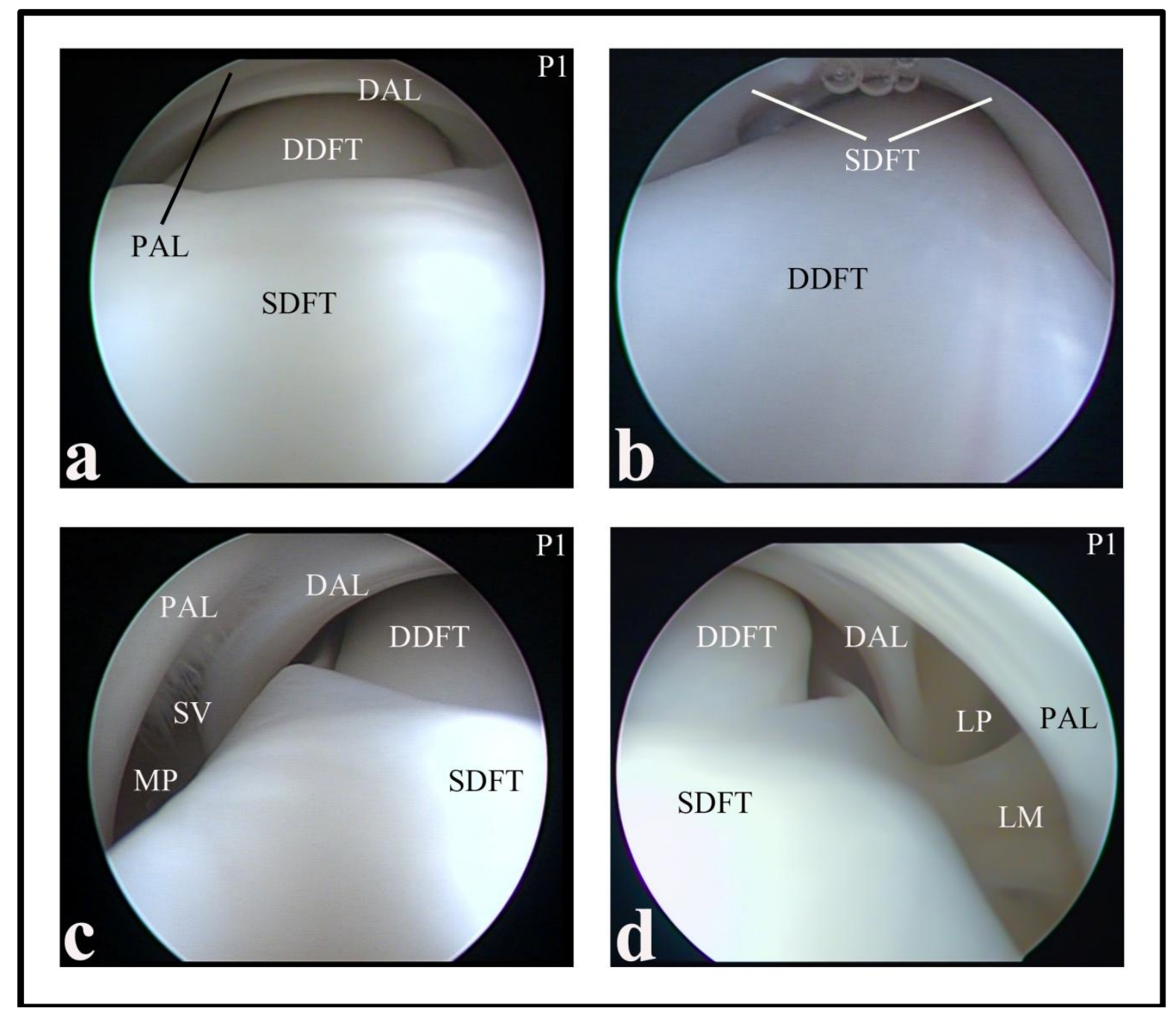

Figure 10. Normal endoscopic views of the common digital flexor tendon sheath (CDFTS). (a): Endoscopic view at P1 showing the plantar aspect of the superficial digital flexor tendon (SDFT) and the deep digital flexor tendon (DDFT) appearing from the end edge of the SDFT; PAL, proximal digital annular ligament; DAL, distal digital annular ligament. (b): Endoscopic view when the arthroscope is introduced in the CDFTS perforating the SDFT (wrong arthroscope access portal); the arthroscope is between the SDFT and the DDFT. (c): Medial endoscopic view at P1: MP, medial pouch; SV, synovial villi. (d): Lateral endoscopic view at P1: LP, lateral pouch; LM, lateral mesotendon. 


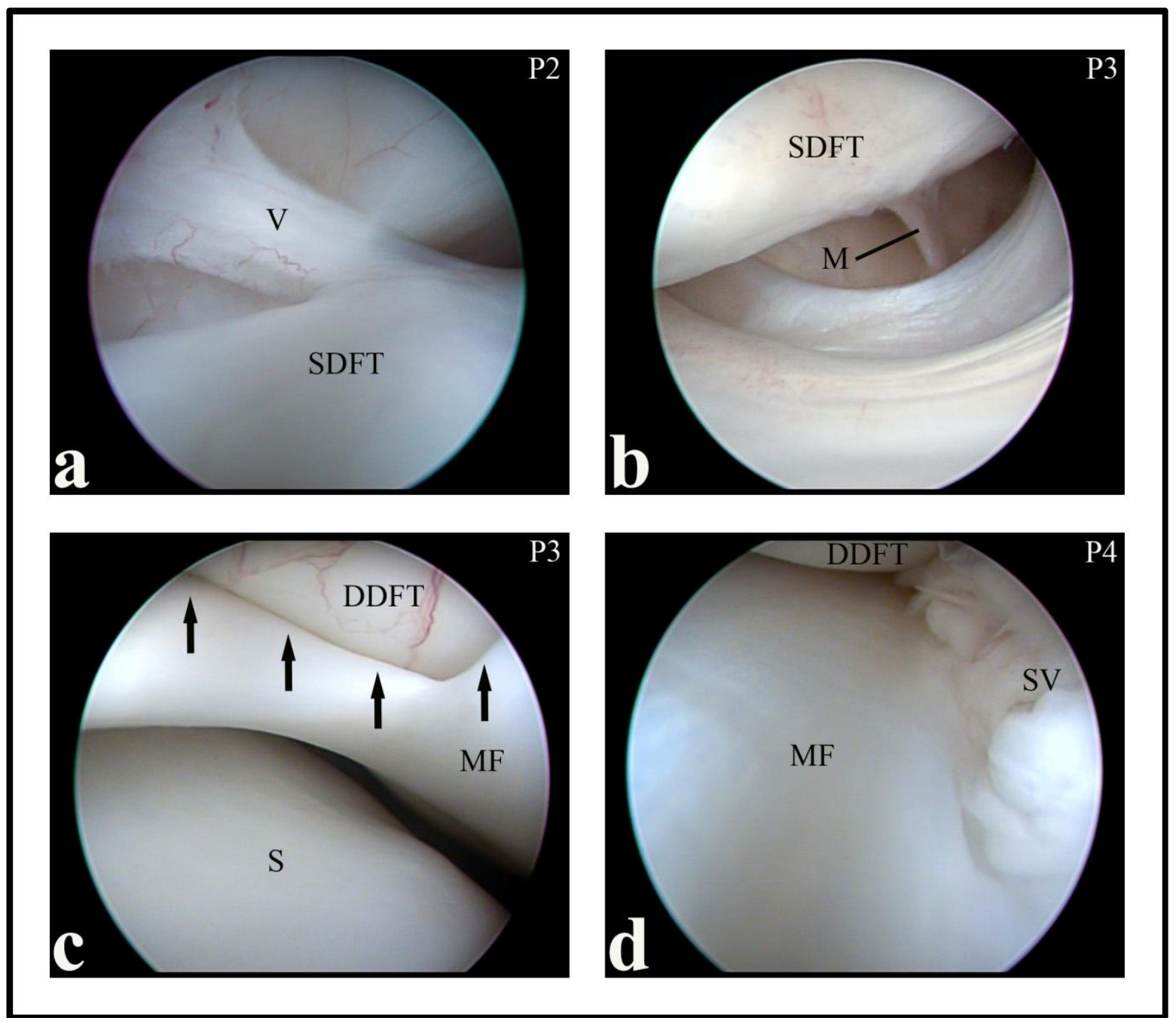

Figure 11. Normal endoscopic views of the common digital flexor tendon sheath (CDFTS). (a): Endoscopic view at P2 showing the medial vinculum tendinum $(\mathrm{V})$ of the superficial digital flexor tendon (SDFT). (b): Distal endoscopic view at P3 showing the distal mesotendon (M). (c): Proximal endoscopic view at P3 at the level of the scutum proximale (S) showing the slot-shaped opening (defined by the black arrows) in the manica flexoria (MF); through this opening the deep digital flexor tendon (DDFT) is visible. (d) Endoscopic view at P4 showing the internal surface of the MF of the SDFT, the DDFT, and synovial villi (SV); in this position, the arthroscope is situated in the inner proximal compartment, between the digital flexor tendons. 


\subsection{Clinical cases}

Below the resume of the CDFTS affected by septic tenosynovitis of the four clinical cases, and the results of the cytology of their synovial fluid.

Table 3. Resume of the clinical cases and the cytology of their synovial fluid.

\begin{tabular}{cccccc}
\hline Case & $\begin{array}{c}\text { CDFTS } \\
\text { involved }\end{array}$ & Lameness & \multicolumn{3}{c}{ Synovial Fluid } \\
\cline { 3 - 6 } & & $\begin{array}{c}\text { Protein } \\
\mathbf{( g / L )}\end{array}$ & $\begin{array}{c}\text { Cell count } \\
\mathbf{( 1 0 ^ { 9 } / \mathbf { L } )}\end{array}$ & $\begin{array}{c}\text { Polymorphonuclear } \\
\text { cells (\%) }\end{array}$ \\
\hline 1 & $\begin{array}{c}\text { Medial/Right } \\
\text { hind limb }\end{array}$ & $4 / 5$ & 45.0 & 96.4 & $90 \%$ \\
\hline 2 & $\begin{array}{c}\text { Lateral/Right } \\
\text { hind limb }\end{array}$ & $3 / 5$ & 32.0 & 36.9 & $96 \%$ \\
\hline 3 & $\begin{array}{c}\text { Lateral/Right } \\
\text { fore limb }\end{array}$ & $4 / 5$ & 40.0 & 26.0 & $92 \%$ \\
\hline 4 & $\begin{array}{c}\text { Lateral/Right } \\
\text { hind limb }\end{array}$ & $3 / 5$ & 69.0 & 118.5 & $94 \%$ \\
\hline
\end{tabular}

\subsubsection{Case 1}

Case 1 was a two-year-old Red Holstein breeding bull with a 4 to 5 day history of lameness and a marked swelling in the fetlock region of the right hind limb. The referring veterinarian had begun systemic antibiotic treatment with penicillin, and on the day before admission had performed centesis of the swelling, revealing the presence of a purulent exudate. On clinical examination, the bull was in fair physical condition but was reluctant to move. Its body temperature was $39.4^{\circ} \mathrm{C}$, breathing was costoabdominal with a rate of 28 breaths/minute, heart rate was 84 beat per minute (bpm), the mucous membranes were pink, and appetite was normal. The bull showed a grade 4/5 lameness (Sprecher et al., 1997) of the right hind limb, with a markedly decreased duration of the retraction phase of the gait. A warm, painful swelling was evident, accentuated over the area of the medial CDFTS, ranging from the pastern to the midmetatarsus. The presence of a wound several days old was evident just above the coronary band of the medial claw. Lateromedial and dorsoplantar radiographs were taken centred over the affected fetlock joint, and revealed moderate soft tissue swelling accentuated at the medial and plantar aspect of the fetlock joint. The bony structures were normal. Ultrasonographic examination of the entire length of both CDFTS and metatarsophalangeal joints was performed, using an $8 \mathrm{MHz}$ linear transducer. The medial CDFTS was severely distended and filled with anechoic fluid interspersed with some hypoechoic areas, while the lateral 
tendon sheath was only slightly distended and filled with homogeneously anechoic fluid. Aspiration from the medial CDFTS yielded an increased amount of synovial fluid, which was turbid, dark yellow and highly viscous. The total nucleated cell count was $96.4 \times 10^{9}$ cells/L, $90 \%$ of which were polymorphonuclear cells. The total protein concentration of the synovial fluid was $45 \mathrm{~g} / \mathrm{L}$ (Tab. 3). Aspiration from the lateral CDFTS yielded dark yellow, viscous synovial fluid with a total nucleated cell count of $3.3 \times 10^{9}$ cells $/ \mathrm{L}, 28 \%$ of which were polymorphonuclear cells, and a total protein concentration of 46 $\mathrm{g} / \mathrm{L}$. Septic tenosynovitis of the medial CDFTS and aseptic tenosynovitis of the lateral CDFTS were diagnosed.

Because of the high breeding value of the bull, the medial CDFTS was investigated by tenovaginoscopy, for prognostic and therapeutic purposes. Tenovaginoscopic inspection revealed that the CDFTS was yielded with a turbid, dark yellow synovial fluid; mild to moderate signs of septic inflammation with an accumulation of small fibrin clots involving most aspects of the CDFTS (Fig. $12 / a)$ were present. Inflammatory processes on the visible aspects of the tendons and sheath were limited to circumscribed areas and were judged to be confined to their surface. In particular the lateral mesotendon was thickened and covered by villi-shaped proliferations (Fig. 12/b).

The lameness and local swelling gradually diminished until day seven after surgery, when the bull was discharged from the hospital. Three months after surgery, telephone follow-up with the owner revealed that a small abscess had developed at the site of the arthroscope portal. After the abscess had been drained, the bull recovered completely and resumed service until the normal end of his productive career.

\subsubsection{Case 2}

Case 2 was a 3 -year-old Simmental cow at the fourth month of pregnancy with a 4-week history of septic tenosynovitis of the lateral CDFTS of the right hind foot. The cow was in fair physical condition. Its body temperature was $38.8^{\circ} \mathrm{C}$, breathing was costoabdominal with a rate of 24 breaths/minute, heart rate was $76 \mathrm{bpm}$, the mucous membranes were pink, appetite and ruminal-enteric activity were normal. The cow showed a grade 3/5 lameness of the right hind limb. The area proximal to the lateral dewclaw of this limb showed a well defined, warm and painful swelling. Radiographs revealed a soft tissue swelling localized at the lateral and plantar aspect of the fetlock joint, and normal bony structures. At the ultrasonography, the lateral CDFTS was distended and filled with hypoechoic fluid with some thin hyperechoic particles; the contralateral CDFTS was judged normal. 


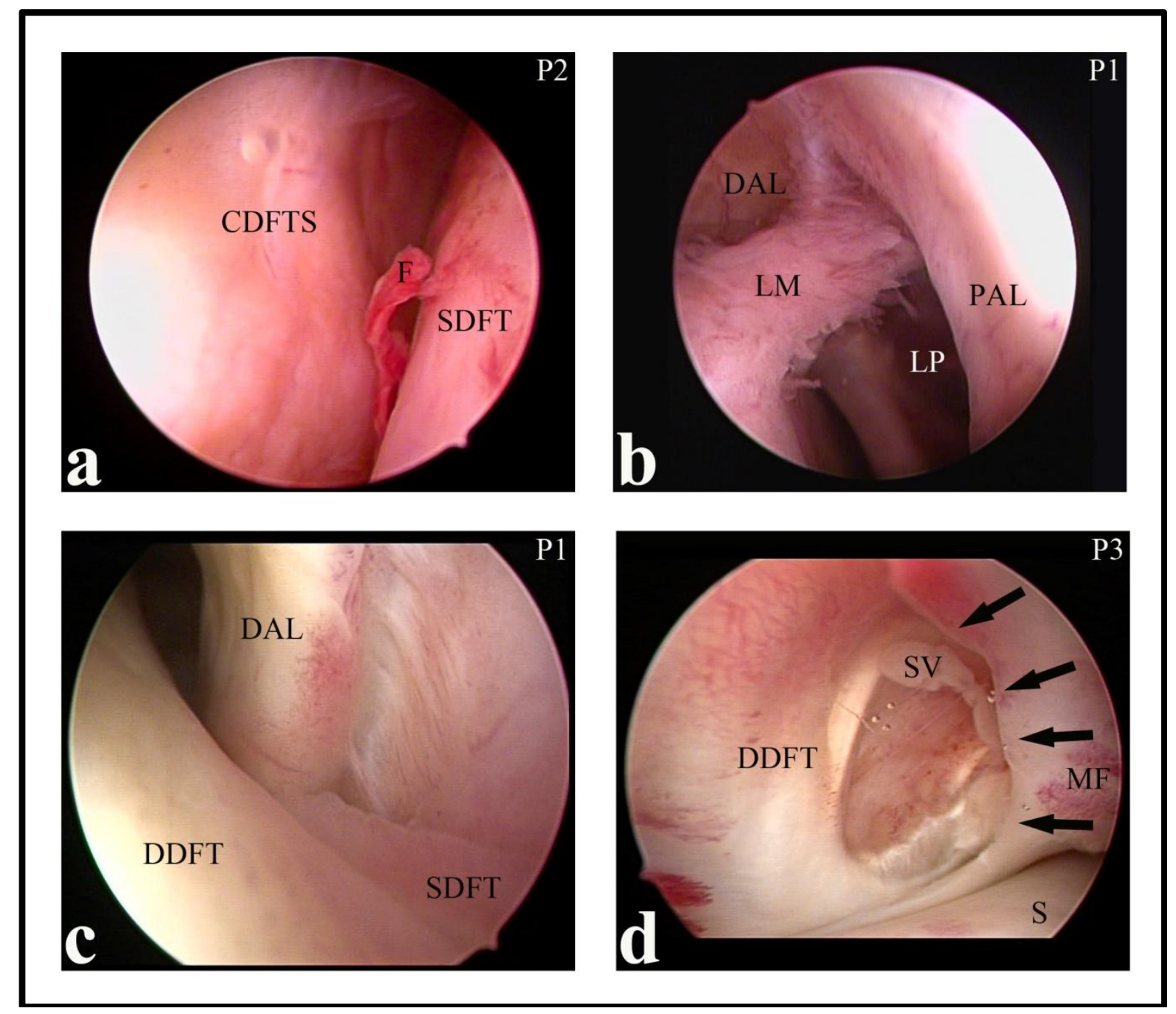

Figure 12. Endoscopic views of pathologic common digital flexor tendon sheath (CDFTS) of clinical case $1(\mathrm{a}, \mathrm{b})$ and 2 (c,d). (a): Case 1, endoscopic view at P2, showing a fibrin clot (F); SDFT, superficial digital flexor tendon. (b): Case 1, lateral endoscopic view at P1, showing the lateral mesotendon (ML) thickened and covered by villi-shaped proliferations; PAL, proximal digital annular ligament; DAL, distal digital annular ligament; LP, lateral pouch. (c): Case 2, medial endoscopic view at P1 showing the end edge of the SDFT and the border of the DAL slightly oedematous and irregular; the surface of the deep digital flexor tendon (DDFT) appears normal. (d): Case 2, P3 endoscopic view at scutum (S) level; the slot-shaped opening (highlighted by the black arrows) of the manica flexoria (MF) has irregular and hyperhaemic border; the DDFT is hyperhaemic and irregular; hypertrophic synovial villi (SV) appears from the space between the digital flexor tendons. 


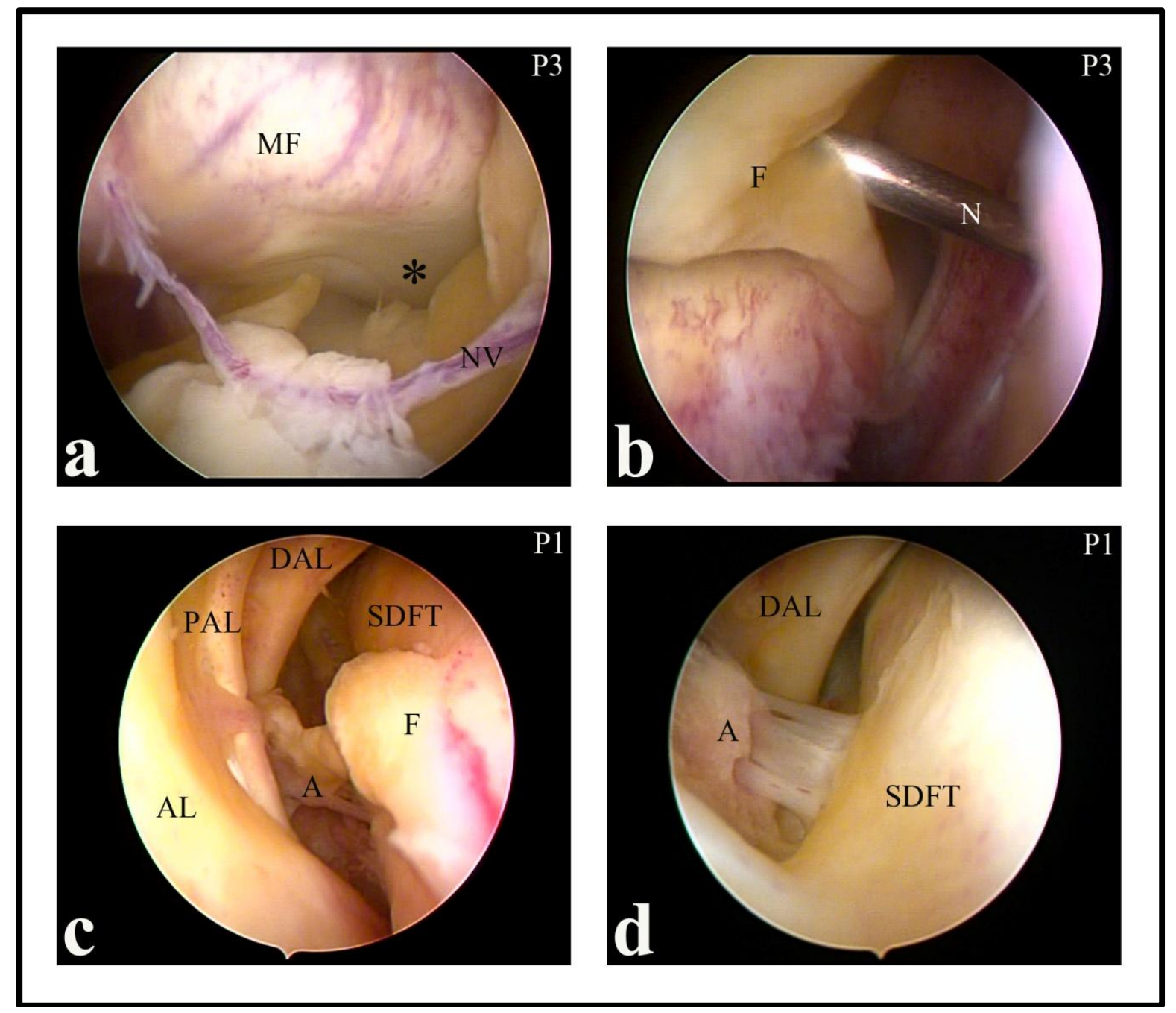

Figure 13. Endoscopic views of pathologic common digital flexor tendon sheath (CDFTS) of clinical case 3 (a,b) and 4 (c,d). (a): Case 3, P3 endoscopic view at scutum level: close-up a newly-formed vessel (NV) with fibrous tissue is visible; the inner surface of the CDFTS appears oedematous; note that the superficial vessels of the manica flexoria (MF) appear congested in the proximal aspect, while the surface appears normal in the distal aspect $\left(^{*}\right)$. (b): Case 3, P3 endoscopic view: insertion of a needle $(\mathrm{N})$ under endoscopic view to perform the lavage of the synovial cavity; close-up a fibrin clot (F). (c): Case 4, endoscopic view at P2 with a lateral perspective: close-up a fibrin clot (F) and the lig. anulare plantare (AL); note the adherence (A) emerging from the lateral pouch; PAL: proximal digital annular ligament; DAL, distal digital annular ligament. (d): Case 4, lateral endoscopic view at P1: a close-up view of the adherence (A) present in Fig 13/c. 
The centesis revealed a synovial fluid turbid, orange and viscous; the total nucleated cell count was $36.9 \times 10^{9}$ cells/L, $96 \%$ of which were polymorphonuclear cells; the total protein concentration of the synovial fluid was $32 \mathrm{~g} / \mathrm{L}$ (Tab. 3). A septic tenosynovitis of the lateral CDFTS was diagnosed. At the tenovaginoscopy, a small amount of free-floating fibrin clots were present, and the superficial blood vessels of the CDTFS appeared congested. At P1, in the lateral pouch, a broad adherence between the SDFT and the CDFTS was visible; medial the distal digital annular ligament and the end edge of the SDFT appeared oedematous, the latter being also irregular (Fig. 12/c). Always at P1, the DDFT appeared quite normal. At P3, the border of the slot-shaped opening was irregular and thickened; also the surface of the DDFT in P3 was hyperaemic and irregular, and the synovial villi of the inner compartment were hypertrophic (Fig. 12/d). The inflammatory processes of the accessible aspects of the tendons and sheath were judged to be confined to their surfaces.

In the follow up, the degree of lameness decreased till $1 / 5$ by day 10 after surgery. At home, the cow made an uneventful recovery and gave birth to a healthy calf at term. Eleven months after surgery, the cow was slaughtered because of infertility.

\subsubsection{Case 3}

Case 3 was a 6-year-old, 4 months pregnant Simmental x Red-Holstein cow. The owner reported that the lameness was noticed after the return from the grazing, two days previously. The general condition of the cow was normal. The body temperature was $38.5{ }^{\circ} \mathrm{C}$, the breathing was costoabdominal with a rate of 30 breaths/minute, the heart rate was $76 \mathrm{bpm}$, the mucous membranes were pink, the appetite and ruminal-enteric activity were normal. The cow showed a grade 4/5 lameness and a touch-down weight-bearing of the right fore limb. The affected foot showed a swelling of the palmar aspect of the fetlock region proximal to the lateral dewclaw. Radiographs revealed a marked soft tissue swelling around the metacarpophalangeal joint, mostly palmar but there was also a small bulge dorsal to the joint; proximally the tendinous structures and the tissue planes could be isolated; within the swollen area the tissues were homogenous. The ultrasonography showed the lateral CDFTS filled with hypoechoic fluid with thin hyperechoic particles; the contralateral CDFTS was judged normal. The synovial fluid was cloudy, turbid, and contained free-floating fibrin clots; the total nucleated cell count was $26.0 \times 10^{9}$ cells/L, $92 \%$ of which were polymorphonuclear cells; the total protein concentration of the synovial fluid was $40 \mathrm{~g} / \mathrm{L}$ (Tab. 3). The diagnosis was septic tenosynovitis of the lateral CDFTS of the right fore limb.

The tenovaginoscopy revealed signs of severe inflammation of the proximal aspects of the CDFTS and the SDFT at P2 and P3. In this area, newly-formed 
blood vessels and fibrin deposits were visible on the inner surface of the CDFTS (Fig. 13/a,b). Superficial blood vessels of the SDFT appeared congested proximal to the fetlock region, but the visible structures appeared normal in the area distal (Fig. 13/a). At P1 and P3 distal, the synovial fluid was turbid and yellowish, but after the lavage (Fig. 13/b) the surface of the DFT and other structures appeared only slightly yellowish, and not hyperaemic. For this reason the inflammatory process was judge to be related to the proximal part of the CDFTS.

Weight bearing of the affected foot had improved by day 5 after surgery. The cow was released from the clinic on day 10 with the right fore foot appearing clinically healed. One year after surgery, the cow was sent to an alpine pasture for a two-month period. On returning to the home farm, the cow presented with a slight lameness of the right fore limb which lasted for 14 days. Thereafter, the lameness resolved completely. At the time of the telephone inquiry, the cow had already calved twice, milk production was judged to be good, and the cow was still a productive member of the herd.

\subsubsection{Case 4}

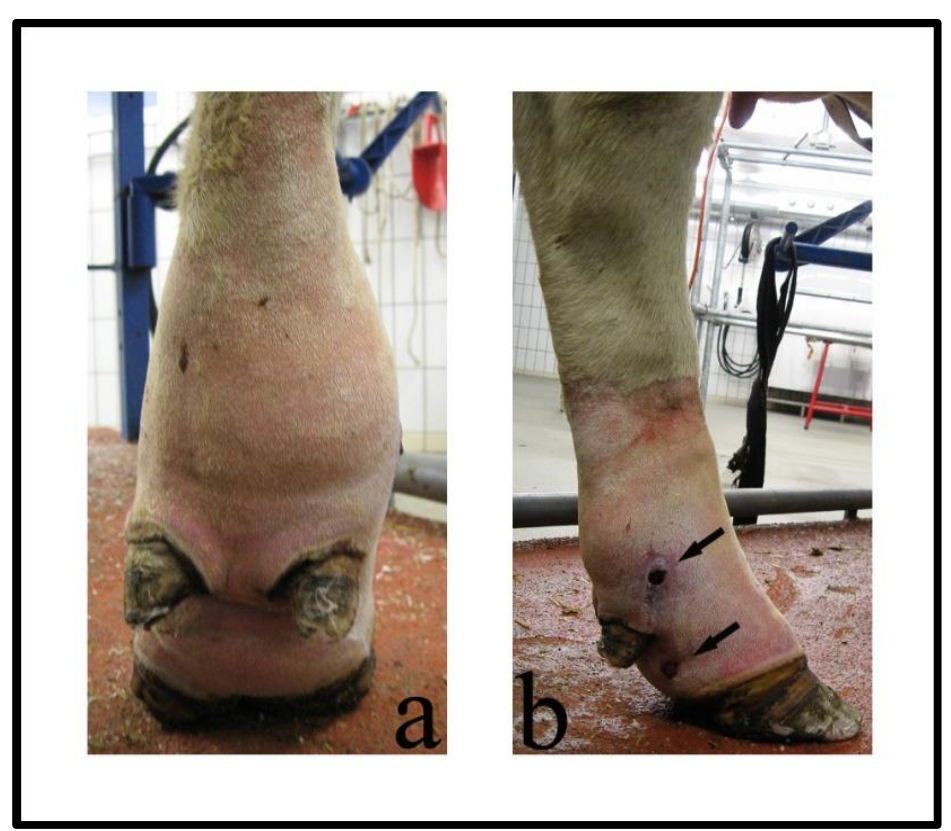

Figure 14. Plantar (a) and lateral (b) views of the right hind foot of case 4; the black arrows indicate the fork wound.
Case 4 was a 7-year-old Red Holstein cow with a 4-week history of septic tenosynovitis of the lateral CDFTS of the right hind foot. The tenosynovitis was the outcome of a penetrating wound made by a fork. The cow was already treated by the referring veterinarian with a systemic antibiotic therapy for 2 times: at the moment of the wound, and 15 days after. At the clinical examination the body temperature was $37,6{ }^{\circ} \mathrm{C}$, breathing was costoabdominal with a rate of 48 breaths/minute, heart rate was $60 \mathrm{bpm}$, the mucous membranes were pink, the appetite and ruminalenteric activity were normal. There was a 3/5 lameness of the right hind limb with a reduction of the gate. This foot had a mild warm fluctuant slightly painful swelling of the lateral fetlock region (Fig. 14/a), with 2 little round wound proximal and distal to the lateral dewclaw (Fig. 14/b). At the radiography, there 
was a homogenous soft tissue swelling localized at the lateroplantar aspect of the fetlock; the bony structures were normal. The ultrasonography showed the lateral CDFTS filled with anechoic fluid with thin hyperechoic fluctuant septa in the proximal pouch; the contralateral CDFTS was judged normal. The synovial cavity was filled with a dark yellowish, cloudy, serofibrinous synovial fluid, containing moderate amounts of free floating fibrin clots; the total nucleated cell count was $118.5 \times 10^{9}$ cells/L, 94\% of which were polymorphonuclear cells; the total protein concentration of the synovial fluid was $69 \mathrm{~g} / \mathrm{L}$ (Tab. 3). Diagnosis of septic serofibrinous tenosynovitis of the lateral CDFTS of the right hind limb was made.

The tenovaginoscopy revealed the presence of newly-formed blood vessels and fibrin clots linked to the SDFT and the CDFTS, mainly at P2 and P1 (Fig. 13/c). Here a fibrous adherence between the lateral pouch and the SDFT was present (Fig. 13/d).The plantar surface of the SDFT appeared reddened and its end edge was irregular. The synovial villi at P3 appeared oedematous. The presence of organized fibrous adhesions between the lateral surface of the SDFT and the CDFTS prevented the exploration of the proximal dorsal aspect of the SDFT. The DDFT showed no alterations.

After surgery, lameness and local swelling gradually diminished over the first seven days, with weight bearing having significantly improved by day 2 . Sent at home, the cow presented a slight swelling of the involved region of the foot and a slight lameness for the following 2 months. Milk production was judged to be good, and the cow remained a productive member of the herd until follow-up 6 months after surgery. 


\section{CHAPTER 5}

\section{Discussion}





\section{Discussion}

The anatomical and ultrasonographic studies allowed tenovaginoscopy to be performed with the full awareness of the structures of a normal CDFTS. This means that in case of tenosynovitis we could distinguish the normal mesotendons and the vinculum tendinum from the eventually new formed adherences or vessels, as in case 2 and 4 . We highlight the importance of the slot-shaped opening of the manica flexoria. This opening was first briefly described by Stanek (1987), and we did not find any other mention in the anatomical literature. In this study, the opening was present only in the hind feet, and in 1 cow only in the lateral digit of its hind feet. This opening allowed an additional proximal communication between the outer and inner proximal compartments; otherwise they communicate only distal, at the end of the SDFT, where they merge together into the distal compartment. Through the slot-shaped opening, the arthroscope can be moved in the proximal inner compartment, between the DFT; this could provide additional information on the progress of disease in cattle with septic tenosynovitis.

In the cadaver feet used in this study and in the clinical cases, we did not find any communication between the 2 CDFTS of the respective foot. This is in agreement with Lischer (1999), who reported that a communication is only present in 10\% of the feet. Lischer stated also that this percentage may increase during the pathological process of tenosynovitis, because the 2 CDFTS are separated only by a thin septum at the fetlock region. On the contrary, Anderson \& St. James (1996) said that a septic tenosynovitis rarely occurs in both tendon sheaths concurrently. They hypothesized that the excessive fibrinous response to intrathecal sepsis, typical of cattle, may serve to localize infection to a single CDFTS.

Ultrasonography is a non invasive diagnostic technique that allows the investigation of the CDFTS and the DFT including their texture, but it does not allow exploration of the area immediately dorsal to the dewclaws (Kofler and Edinger, 1995). In the horse, some Authors (Nixon, 2002; Edinger et al., 2005) reported that ultrasonography is relatively insensitive in detecting minor irregularities and linear defects of the tendon surfaces, and adhesions of fibrin clots to the internal synovial cavity. In case 4, it was only during tenovaginoscopy that the border of the SDFT was found to be irregular, and in cases 2 and 4, the adhesions were only identified during tenovaginoscopy. Other internal structure of the CDFTS could not be visualized as the mesotendons, the vinculum tendinum and the slot-shaped opening. These structures could be investigated only by tenovaginoscopy. However, ultrasonography remains an essential step in the diagnosis and the evaluation of the tenosynovitis of the CDFTS. Only after an ultrasonography we could decide if the patient is eligible 
for a tenovaginoscopy. Extensive damages to the texture of the tendons and/or a CDFTS contents completely organized preclude the success of a tenovaginoscopic lavage. In these cases, the conventional surgical techniques may be more appropriate.

The tenovaginoscopic technique described used an arthroscope access portal proximal to the lig. anulare palmare/plantare. This choice was motivated by the presence of the dewclaws, which cover the distal border of this ligament. This access allowed a complete and direct inspection of the CDFTS. However, structures distal to the distal digital annular ligament were not inspected, because of the limited length of the arthroscope $(18 \mathrm{~cm})$ and because the tightness of the distal interdigital ligament, that limits the endoscope to be proceeded. We were also not able to visualize the proximal pouch of the inner proximal compartment. This pouch could be site of severe adhesions and fibrin deposits during a septic tenosynovitis. This compartment is only accessible by the slotshaped opening in the manica flexoria of the hind feet, which is situated distal to our arthroscope portal. As a theoretical alternative, the space between the tendons (P4) of the fore limbs and the proximal pouch of the inner proximal compartment may be reached by artificial perforation of the palmar/plantar surface of the SDFT. This may cause considerable damage to the tendon, we thus suggest avoiding this access portal. Inadvertent perforation of the SDFT may occur if the arthroscope access portal is made on the lig. anulare palmare/plantare. In our study this eventuality occurred 3 times in the cadaver tenovaginoscopic study. The accurate choice of the arthroscope access portal is essential to prevent mistakes and damage to the SDFT during the introduction of the sleeve in the synovial cavity.

For the tenovaginoscopy, it is mandatory that the involved limb is absolutely motionless. For this purpose, the standard general anaesthesia protocol of the Clinic for Ruminants of the Vetsuisse Faculty, University of Bern, with emphasis on accurate pain management, was advocated. As an alternative more economic and following the EU drug regulations, tenovaginoscopy of the hind limbs may be performed after sedation of the cow with xylazine, associated to either an epidural or an intravenous regional anaesthesia with lidocaine or procaine.

In general, treatment of the CDFTS tenosynovitis may include local and/or systemic administration of antimicrobials, multifenestrated indwelling lavage, synoviotomy with surgical debridement with or without partial resection of the DFT, or amputation of the affected digit (Anderson and St. Jean, 1996; Desrochers et al,, 2001). In the four clinical cases presented, the tenovaginoscopy allowed extensive lavage of the CDFTS under visual control, to dilute inflammatory mediators and bacteria present in the sheath, and to flush out small fibrin clots and reduce the tendency for further adhesions to form. This procedure enabled the evaluation of the superficial aspects of the CDFTS 
and the DFT with minimal damage to these structures compared to other conventional techniques. The adhesions seen in case 2 and 4 , and the fibrin deposits present in cases 3 and 4 were considered as indicators of a moderate to poor prognosis. Specific additional intraoperative measures, as an additional instrument portal for introduction of an endoscopic tissue forceps, were not taken. Despite the fact that two of our cases had a history of tenosynovitis of at least 4 weeks duration already pre-treated with antimicrobials by the referring veterinarian, the outcome of all four cases was favourable in both the short and the long term.

About the cost and the use of the tenovaginoscopy of the CDFTS in cattle, we are conscious that this technique finds a low application in field condition, mainly because of the cost of the arthroscopic instruments; about the patient restraint, we had proposed cheaper and easier alternatives. The technique was thought and developed as a diagnostic and operative support for the clinics for ruminants. This is a new situation in the Italian cattle context, but clinics for ruminants are a long time consolidated reality in other countries as Swiss (the study was undertaken in the Clinic for Ruminants of Bern), German, Austria, USA, Canada, where they have both a didactic and supportive of the field practitioners functions.

The results of this study warrant further clinical use of tenovaginoscopy of the CDFTS in order to better evaluate and identify the limits of this minimally invasive approach. 

Conclusions 



\section{Conclusions}

Tenovaginoscopy of the CDFTS in cattle is a minimally invasive technique that has diagnostic, prognostic and therapeutic applications. Ultrasonography remains an essential instrument for the first diagnostic approach to diseases of the CDFTS. Tenovaginoscopy is superior to ultrasonography in terms of visualisation of pathological changes, and it allows for the concurrent treatment of septic processes under visual control. Further investigations, however, are needed to evaluate the limits of lavage of the CDFTS under visual control as compared with alternative, more invasive techniques such as tenovaginotomy and amputation of the digit. 

Summary 



\section{Summary}

The aim of this study was to describe the tenovaginoscopic approach to the bovine common digital flexor tendon sheath (CDFTS). An anatomical, ultrasonographic and endoscopic study was undertaken using 27 healthy cadaver feet from 7 adult dairy cows. Tenovaginoscopy was performed using a rigid, $30^{\circ}$ arthroscope (length $18 \mathrm{~cm}$ and outer diameter $4 \mathrm{~mm}$ ), enabling a direct view of the synovial cavity and the following structures: digital flexor tendons, digital annular ligaments, lateral and medial pouches, 3 mesotendons, a vinculum tendinum and a slot-shaped opening in the manica flexoria of the hind feet. Additionally, four clinical cases of septic tenosynovitis treated with lavage under tenovaginoscopic control were examined. Tenovaginoscopy represents a minimally invasive method for diagnosis and treatment of septic tenosynovitis of the CDFTS, which allows the degree of alterations of the normal structures to be evaluated. 



\section{References}





\section{References}

Anderson, D.E., St-Jean, G., Morin, D.E., Ducharme, N.G., Nelson, D.R., Desrochers, A., 1996. Traumatic flexor tendon injuries in 27 cattle. Veterinary Surgery 25, 320-326.

Anderson, D.E., St. Jean, G., 1996. Diagnosis and management of tendon disorders in cattle. Veterinary Clinics of North America-Food Animal Practice 12, 85-116.

Anderson, D.E., Allen, D., St-Jean, G., Parks, A.H., 1997. Use of a multifenestrated indwelling lavage system for treatment of septic digital tenosynovitis in cattle. Australian veterinary journal 75, 796-799.

Bailey, J., 1997. Wounds. In: Greenough, P.R., Weaver, A.D. (Eds.), Lameness in cattle. W. B. Saunders, Philadelphia, pp. 181-188.

Bertone, A.L., 1996. Infectious arthritis. In: Mcllwrith, C.W., Trotter, G.W. (Eds.), Joint Disease in the Horse. WB Saunders Company, Philadelphia, pp. 397-409.

Cook, V.L., Bertone, A.L., 1998. Infectious arthritis. In: White, N.A., Moore, J.N. (Eds.), Current techniques in equine surgery and lameness. WB Saunders Company, Philadelphia, pp. 381-385.

Desrochers, A., Anderson, D.E., St-Jean, G., 2001. Surgical treatment of lameness. Veterinary Clinics of North America-Food Animal Practice 17, 143-158.

Desrochers, A., 2004. Septic arthritis. In: Fubini, S.L., ducharme, N.G. (Eds.), Farm animal surgery. Saunders, St. Louis, pp. 330-336.

Dirksen, G., Gründer, H.D., Stöber, M. (Eds.), 2002. Medicina interna e chirurgia del bovino. Le Point Vétérinaire Italie srl, Milano, Italia.

Edinger, J., Mobius, G., Ferguson, J., 2005. Comparison of tenoscopic and ultrasonographic methods of examination of the digital flexor tendon sheath in horses. Veterinary and Comparative Orthopedics and Traumatology 18, 209-214. 
Fraser, B.S.L., Bladon, B.M., 2004. Tenoscopic surgery for treatment of lacerations of the digital flexor tendon sheath. Equine Veterinary Journal 36, 528-531.

Frees, K.E., Lillich, J.D., Gaughan, E.M., DeBowes, R.M., 2002. Tenoscopicassisted treatment of open digital flexor tendon sheath injuries in horses: 20 cases (1992-2001). Journal of the American Veterinary Medical Association 220, 1823-1827.

Gaughan, E.M., 1996. Arthroscopy in food animal practice. The Veterinary Clinics of North America-Food animal practice 12, 233-247.

Greenough, P.R., MacCallum, F.J., Weaver, A.D., 1981a. Treatment and control of digital disease. In: Greenough, P.R., MacCallum, F.J., Weaver, A.D. (Eds.), Lameness in cattle. Lippincot, Philadelphia, pp. 228-262.

Greenough, P.R., MacCallum, F.J., Weaver, A.D., 1981b. Diseases of soft tissues. In: Greenough, P.R., MacCallum, F.J., Weaver, A.D. (Eds.), Lameness in cattle. Lippincot, Philadelphia, pp. 228-262.

Kofler, J., 1994. Ultrasonography as a new tool for diagnosis of septic tenosynovitis of the digital flexor tendon sheath in cattle - therapy and long term follow-up. Deutsche Tierärztliche Wochenschrift 101, 215-222.

Kofler, J., Edinger, H.K., 1995. Diagnostic ultrasound imaging of soft tissues in the bovine distal limb. Veterinary Radiology \& Ultrasound 36, 246-252.

Kofler, J., 1996. Ultrasonographic imaging of pathology of the digital flexor tendon sheath in cattle. Veterinary Record 139, 36-41.

Kofler, J., Martinek, B., 2005. New surgical approach to the plantar fetlock joint through the digital flexor tendon sheath wall and suspensory ligament apparatus in cases of concurrent septic synovitis in two cattle. Veterinary Journal 169, 370-375.

Kofler, J., 2009. Ultrasonography as a diagnostic aid in bovine musculoskeletal disorders. The Veterinary Clinics of North America-Food animal practice $25,687-731$.

Lischer, C. (Ed.), 1999. Manuel des soins et traitements des onglons chez le bovin. Merkur Druck AG, Lagenthal. 
Lopes, M.A.F., Sullins, K.E., Walker, B.L., 2006. Tenoscopy in 33 horses with septic and nonseptic digital tenosynovitis (1997-2001). Journal of Equine Veterinary Science 26, 27-31.

Madison, J.B., Sommer, M., Spencer, P.A., 1991. Relations among synovial membrane histopathologic findings, synovial fluid cytologic findings, and bacterial culture results in horses with suspected infectious arthritis: 64 cases (1979-1987). Journal of the American Veterinary Medical Association 198, 1655-1661.

MCIlwraith, C.W., 1990. Other uses of arthroscopy in the horses. In: MCIlwraith, C.W. (Ed.), Diagnostic and surgical arthroscopy in the horse. Lea \& Febiger, Philadelphia, pp. 219-223.

Morandi, N., Bertagnoli, A., Steiner, A., 2009. Tenovaginoscopic lavage for treatment of septic tenosynovitis in a breeding bull. Veterinary Record $165,415-416$.

Munroe, G.A., Cauvin, E.R., 1994. The use of arthroscopy in the treatment of septic arthritis in 2 highland calves. British Veterinary Journal 150, 439 449.

Nixon, A.J., 1990. Endoscopy of the digital flexor tendon sheath in horses. Veterinary Surgery 19, 266-271.

Nixon, A.J., 2002. Arthroscopic surgery of the carpal and digital tendon sheaths. Clinical Techniques in Equine Practice 4, 245-256.

Sprecher, D.J., Hostetler, D.E., Kaneene, J.B., 1997. A lameness scoring system that uses posture and gait to predict dairy cattle reproductive performance. Theriogenology 47, 1179-1187.

Stanek, C., 1987. Morphologische, funktionelle, chemische und klinische Untersuchungen zu den Erkrankungen der Fesselbeugesehnenscheide des Rindes. Wiener Tierarztliche Monatsschrift 74, 397-412.

Stanek, C., 1988. Morphologische, funktionelle, chemische und klinische Untersuchungen zu den Erkrankungen der Fesselbeugesehnenscheide des Rindes. Wiener Tierarztliche Monatsschrift 75, 127-138. 
Stanek, C., 1997. Tendons and tendon sheaths. In: Greenough, P.R., Weaver, A.D. (Eds.), Lameness in cattle. W. B. Saunders, Philadelphia, USA, pp. 188-190.

Starke, A., Heppelmann, M., Meyer, H., Rehage, J., 2008. Diagnostic and therapy of septic arthritis in cattle. Cattle Practice 16, 36-43.

Steiner, A., Hirsbrunner, G., Miserez, R., Tschudi, P., 1999. Arthroscopic lavage and implantation of gentamicin-impregnated collagen sponges for treatment of chronic septic arthritis in cattle. Veterinary and Comparative Orthopaedics and Traumatology 12, 64-69.

Steiner, A., 2008. Clinical and imaging procedures for lameness diagnosis in cattle. Magyar Mezogazdasag Kiado 130, 104-106.

Verschooten, F., De Moor, A., Steenhaut, M., Desmet, P., Wouters, L., De Ley, G., 1974. Surgical and conservative treatment of infectious arthritis in cattle. Journal of the American Veterinary Medical Association 165, 271 275.

Weaver, A.D., 1997. Joint condition. In: Greenough, P.R., Weaver, A.D. (Eds.), Lameness in cattle. W. B. Saunders, Philadelphia, pp. 162-170.

Wright, I.M., Smith, M.R.W., Humphrey, D.J., Eaton-Evans, T.C.J., Hillyer, M.H., 2003. Endoscopic surgery in the treatment of contaminated and infected synovial cavities. Equine Veterinary Journal 35, 613-619. 


\section{Acknowledgments}





\section{Acknowledgments}

These acknowledgments are written in three different languages, because I want that they will be more understandable for the people I dedicated them. I am sorry for the Suisse People, I still not talk German.

I want to tank first Professor Adrian Steiner. He greeted me in his wonderful clinic, he provides me all the instruments (he let me use in complete autonomy all the arthroscopic instrumentation, maybe he loves the risk), he brings me in Marseille and in Munich. He was a careful supervisor of this study, and I think that without him, this study it will not be undertaken, mainly because it comes from a Prof. Steiner's idea.

Many thanks to Dr. Marta Räber, for her always enthusiastic help in the anatomical study.

Then, I want to thank my tutor, Prof. Carlo Maria Mortellaro, for granting me his confidence and full autonomy in my work.

Special thanks to all the vets of the Wiederkäuer klinik von Bern! To Bessy for her infinite patient and kindness, I really learned a lot of things from you, thanks! A Patrizia, opérer avec toi a été toujours un grand plaisir! A Pascal, parce que tu es une femme très difficile mais aussi très intelligente et surtout amusante. To Michelle for her minestrone! A Davide parce que tu as été un amis très important! C'est damage que nous ne réussissons pas à se tenir en communication. To Claudia for the translations of the clinical records. A Marie qui a été toujours la première personne que j’ai rencontrée à la Clinique. To Astrid, I never had a guard with you. Sorry it wasn't my fault! To Prof. Hirsbrunner, always calm and smiling. Grazie a Nicole, praticamente l'unica voce italiana nei 6 mesi trascorsi a Berna. And many thanks also to Franzin, Patrick, Vincent, Marcus, and Martin (all the best for your work).

Mercis beaucoup au Professeur Mireille Meinlan. Surtout pour m'avoir fait connaitre les croissants de Glatz et pour la conversation sur le train en retour de Munich. Mercis aussi pour votre enseignements, çà va sans dire.

E adesso un po' d'italiano.

Grazie al Prof. Angelo Belloli, che mi ha seguito negli ultimi 4 anni. È e sarà per sempre un punto di riferimento nella mia vita professionale e non. Quello che sono oggi è anche merito (o colpa) sua. Grazie Prof..

Grazie al Dr. Davide Pravettoni, veterinario, ricercatore, parà, e negli ultimi anni anche ispirato fotoreporter. Grazie per tutto quello $\mathrm{mi}$ hai insegnato, ma soprattutto, grazie per le foto! Elena ed io non potremmo avere miglior ricordo di quel giorno.

Grazie al Dr. Nicola Morandi in arte Nik. Collega, filosofo, Gran Visir di un elenco interminabile di cose che sarebbe inutile e noioso star qui a elencare (anche se lui scommetto che ci terrebbe). Ma soprattutto amico e importante 
sostegno in questi 4 anni di Clinica dei Ruminanti e del Suino (e Management). Mi mancheranno le nostre chiacchierate di mezzogiorno.

Un pensiero speciale alla Dott.sa Valentina Locatelli, l'animo femminile della nostra Clinica e instancabile fornitrice di dolcini e biscottini sfiziosi. Resta sempre così.

Una menzione d'onore all'allegra brigata di Lodi: Davide, Antonio, Dodi, Sara, Marco, Pietro, Giovanni, Bianca, Claudia, Piero, Marta, Marianna, Max, Alessandro...

Come potrei dimenticare poi l'esercito di interni che mi sono passati tra le mani in questi anni. Alcuni di voi ormai sono diventati colleghi, altri lo saranno presto. Riccardo, Alberto, Ricardo, Alessio, Mara, Noemi (con cui ho condiviso la mia prima chirurgia addominale d'urgenza completamente soli la notte di capodanno), Veronica, Anna, Silvia, Roberta, Veronica, Eleonora, Giorgia, Cesare, Martino, Mattia, Seco, Alessandro... (Non me ne voglia chi ho sbadatamente omesso, ma siete veramente tanti!).

Per ultimi ho lasciato chi mi sta da sempre vicino. Elena, con cui ho da poco iniziato un'avventura lunga come la vita, e che mi sta sostenendo e sopportando in questi ultimi 4 mesi.

Infine le nostre 2 famiglie che mai ci hanno fatto mancare il loro appoggio. Se siamo arrivati sin qui, è anche merito vostro. Grazie. 